\title{
Tropical Atlantic dust and smoke aerosol variations related to the Madden-Julian Oscillation in MODIS and MISR observations
}

\author{
Yanjuan Guo, ${ }^{1,2}$ Baijun Tian, ${ }^{1}$ Ralph A. Kahn, ${ }^{3}$ Olga Kalashnikova, ${ }^{1}$ Sun Wong, ${ }^{1}$ \\ and Duane E. Waliser ${ }^{1}$ \\ Received 7 January 2013; revised 10 April 2013; accepted 10 April 2013; published 28 May 2013.
}

[1] In this study, Moderate Resolution Imaging Spectroradiometer (MODIS) fine mode fraction and Multi-angle Imaging SpectroRadiometer (MISR) nonspherical fraction data are used to derive dust and smoke aerosol optical thickness $\left(\tau_{\text {dust }}\right.$ and $\left.\tau_{\text {smoke }}\right)$ over the tropical Atlantic in a complementary way: due to its wider swath, MODIS has 3-4 times greater sampling than MISR, but MISR dust discrimination is based on particle shape retrievals, whereas an empirical scheme is used for MODIS. MODIS and MISR show very similar dust and smoke winter climatologies. $\tau_{\text {dust }}$ is the dominant aerosol component over the tropical Atlantic, accounting for $40-70 \%$ of the total aerosol optical thickness (AOT), whereas $\tau_{\text {smoke }}$ is significantly smaller than $\tau_{\text {dust }}$. The consistency and high correlation between these climatologies and their daily variations lends confidence to their use for investigating the relative dust and smoke contributions to the total AOT variation associated with the Madden-Julian Oscillation (MJO). The temporal evolution and spatial patterns of the $\tau_{\text {dus }}$ anomalies associated with the MJO are consistent between MODIS and MISR: the magnitude of MJO-realted $\tau_{\text {dust }}$ anomalies is comparable to or even larger than that of the total $\tau$, while the $\tau_{\text {smoke }}$ anomaly represents about $15 \%$ compared to the total, which is quite different from their relative magnitudes to the total $\tau$ on the climatological time scale. This suggests that dust and smoke are not influenced by the MJO in the same way. Based on correlation analysis, dust is strongly influenced by the MJO-modulated trade wind and precipitation anomalies, and can last as long as one MJO phase, whereas smoke is less affected.

Citation: Guo, Y., B. Tian, R. A. Kahn, O. Kalashnikova, S. Wong, and D. E. Waliser (2013), Tropical Atlantic dust and smoke aerosol variations related to the Madden-Julian Oscillation in MODIS and MISR observations, J. Geophys. Res. Atmos., 118, 4947-4963, doi:10.1002/jgrd.50409.

\section{Introduction}

[2] The Madden-Julian Oscillation (MJO) [Madden and Julian, 1971, 1972] is the dominant form of intraseasonal (30-90 day) variability in the tropical atmosphere. It is characterized by slow $\left(\sim 5 \mathrm{~m} \mathrm{~s}^{-1}\right)$ eastward-propagating, large-scale oscillations in the tropical deep convection over the equatorial Indian Ocean and western Pacific during boreal winter (November-April) [Lau and Waliser, 2005; Zhang, 2005]. Recently, there is strong emerging interest in the impacts of the MJO on atmospheric composition [Tian and Waliser, 2011], such as aerosol [Tian et al., 2008, 2011; Reid et al., 2012], ozone [Tian et al., 2007; Weare, 2010; Li et al.,

\footnotetext{
${ }^{1}$ Jet Propulsion Laboratory, California Institute of Technology, Pasadena, California, USA.

${ }^{2}$ Joint Institute for Regional Earth System Science \& Engineering, University of California, Los Angeles, California, USA.

${ }^{3}$ NASA Goddard Space Flight Center, Greenbelt, Maryland, USA.

Corresponding author: B. Tian, Jet Propulsion Laboratory, M/S 233-304, California Institute of Technology, 4800 Oak Grove Dr., Pasadena, CA 91109, USA. (baijun.tian@jpl.nasa.gov)

(C)2013. American Geophysical Union. All Rights Reserved. 2169-897X/13/10.1002/jgrd.50409
}

2011], carbon dioxide [Li et al., 2010], and carbon monoxide [Wong and Dessler, 2007].

[3] Tian et al. [2008] first examined the aerosol variability related to the MJO using global aerosol products from multiple sensors on various satellite platforms. That study revealed large intraseasonal variations in the satellite-derived aerosol products over the tropics, though the interpretation in terms of actual aerosol behavior was ambiguous as inconsistent aerosol vs. MJO-wet-phase relationships are found between different satellite aerosol data sets. Possible reasons leading to the inconsistency include the aerosol humidification effect, wet deposition, low-level wind effect, biological production, sampling effect, and cloud contamination. Tian et al. [2011] further investigated the MJO-related aerosol variability over the tropical Atlantic Ocean using the aerosol optical thickness (AOT) product from the MODIS (Moderate Resolution Imaging Spectroradiometer) on the Aqua satellite. They suggested that the MJO-related intraseasonal variance accounts for about $25 \%$ of the total AOT variance over the tropical Atlantic. They also found that the MJO modulates the Atlantic aerosol variation primarily through its influence on the Atlantic low-level zonal winds. Given the potential predictability of the MJO extending to 2-4 weeks [e.g., Waliser, 2005], the study by Tian et al. [2011] implies that the Atlantic aerosol concentration may be predictable with 
lead times of 2-4 weeks, which in turn may lend important guidance to predicting air quality, dust storm activity, and ocean nutrient deposition over the Atlantic Ocean.

[4] Nevertheless, Tian et al. [2011] examined only the total AOT anomalies and did not consider the contribution of different aerosol types to the total AOT anomalies. It is well known that the aerosol over the tropical Atlantic Ocean in the boreal winter season is a mixture of mineral dust from the Sahara desert and the Sahel region, biomass burning smoke from the Sahel and African savanna regions, and marine aerosol (primarily sea salt and secondly sulfate aerosols) from the ocean surface [Kaufman et al., 2002, 2005a, 2005b]. Because dust, biomass burning smoke and marine aerosols play very different roles in the radiative forcing and cloud formation process, it is of great interest to partition the total aerosol into individual aerosol components and examine the MJO-related variability in each aerosol type.

[5] In this study, we use two independent satellite data sets, MODIS and MISR (Multi-angle Imaging SpectroRadiometer), to investigate the intraseasonal variability of individual aerosol components related to the MJO over the tropical Atlantic. These two data sets both have their advantages and disadvantages, thus are complementary to each other: MODIS has more frequent sampling than MISR due to its wider swath, but the scheme used to distinguish dust and smoke is subject to some major assumptions. MISR discriminates dust aerosol using actual particle shape information, however, it cannot distinguish smoke from other spherical components, and it has only $1 / 4$ to $1 / 3$ times sampling of MODIS.

[6] The rest of this paper is organized as follows. Section 2 describes the MODIS and MISR data, and the methodology used to derive specific aerosol components from the total AOT. The climatology of specific aerosol components as well as the comparison of dust aerosol between MODIS and MISR is presented in section 3 to examine the fidelity of the methods described in section 2 . The main results of this paper, the MJO-related dust and smoke aerosol anomalies and correlations with MJO-related wind and precipitation anomalies, are presented in section 4. Conclusions and discussions are presented in section 5.

\section{Methodology and Data Description}

\subsection{Moderate Resolution Imaging Spectroradiometer}

[7] Previous studies [Kaufman et al., 2002, 2005a, 2005b] have suggested that satellite data distinguishing fine-mode aerosols from coarse-mode aerosols could be used to separate the aerosol into specific types, because different aerosol types (e.g., smoke, dust, and marine aerosols) have different fine mode fraction $(f)$ values. $f$ is the fraction of total midvisible AOT contributed by the fine-mode aerosols. In MODIS, the fine-mode aerosols refer to the aerosols with a size distribution of radii centered between 0.1 and $0.25 \mu \mathrm{m}$, whereas the coarse-mode aerosols have radii centered between 1 and $2.5 \mu \mathrm{m}$. In their series of studies [Kaufman et al., 2002, 2005a, 2005b], they developed empirical formulae to estimate dust and smoke aerosols using MODIS/ Terra AOT and $\mathrm{f}$ observations. These formulae have since been widely adopted by the community to understand aerosol types and their climate forcing [e.g., Bellouin et al., 2005; Yu et al., 2009, among many others].With the two constraints that both the total AOT and its fine mode fraction can be partitioned into contributions from the dust, smoke, and marine aerosol components, we have the following equations:

$$
\begin{gathered}
\tau=\tau_{\text {dust }}+\tau_{\text {smoke }}+\tau_{\text {mar }} \\
f \times \tau=f_{\text {dust }} \times \tau_{\text {dust }}+f_{\text {smoke }} \times \tau_{\text {smoke }}+f_{\text {mar }} \times \tau_{\text {mar }}
\end{gathered}
$$

[8] Rewriting (1) and (2), we get

$$
\begin{gathered}
\tau_{\text {dust }}=\left[\tau \times\left(f_{\text {smoke }}-f\right)-\tau_{\text {mar }} \times\left(f_{\text {smoke }}-f_{\text {mar }}\right)\right] /\left(f_{\text {smoke }}-f_{\text {dust }}\right) \\
\tau_{\text {smoke }}=\left[\tau \times\left(f-f_{\text {dust }}\right)-\tau_{\text {mar }} \times\left(f_{\text {mar }}-f_{\text {dust }}\right)\right] /\left(f_{\text {smoke }}-f_{\text {dust }}\right)
\end{gathered}
$$

[9] In these equations, $\tau$ denotes total midvisible AOT ( $\tau$ and AOT are used interchangeably in this paper), and the subscripts "dust", "smoke", and "mar" indicate dust, smoke, and marine aerosol components, respectively. With $\tau$ and $f$ being MODIS measurements, $\tau_{\text {dust }}$ and $\tau_{\text {smoke }}$ can be computed directly if $f_{\text {dust }}, f_{\text {smoke }}, f_{\text {mar }}$, and $\tau_{\text {mar }}$ are known.

[10] In the Kaufman et al. study, $f_{\text {dust }}, f_{\text {smoke, }}$, and $f_{\text {mar }}$ are assumed to be constant, and were derived by averaging the MODIS/Terra $f$ observations over selected regions and time periods where one specific aerosol type dominates, with their uncertainties estimated from these selected measurements: $f_{\text {dust }}=0.5 \pm 0.05, f_{\text {smoke }}=0.9 \pm 0.05$, and $f_{\text {mar }}=0.3$ \pm 0.1 [Kaufman et al., 2005a]. However, the actual $f$ values vary with season and location [e.g., Maring et al., 2003; Yu et al., 2009], thus large uncertainties are expected from using constant $f_{\text {dust }}, f_{\text {smoke }}, f_{\text {mar }}$ when applying Kaufman's formula. More discussion of this issue as well as the sensitivity of our results to the $f$ values adopted will be given in section 4.3 .

[11] The marine AOT, $\tau_{\text {mar }}$, depends strongly on surface wind speed, as its primary component is sea-spray salt [Huang et al., 2010; Smirnov et al., 2003]; it is estimated using the empirical formula in Kaufman et al. [2005a]

$$
\tau_{\text {mar }}=0.007 W+0.02
$$

[12] Here $W$ is the surface $(10 \mathrm{~m})$ wind speed from the European Centre for Medium-Range Weather Forecasts (ECMWF) ERA-Interim reanalysis [Dee et al., 2011]. The global mean value of $\tau_{\text {mar }}$ is around $0.06 \pm 0.005$ [e.g., Kaufman et al., 2001].

[13] In this study, daily AOT and $f$ measurements at $0.55 \mu \mathrm{m}$ from the MODIS/Aqua Level-3 Collection 5.1 data set [Remer et al., 2005; Levy et al., 2009] on $1^{\circ} \times 1^{\circ}$ spatial grids are used. The uncertainties of $\tau$ are $\pm(0.03+0.05 \tau)$ over ocean and $\pm(0.05+0.15 \tau)$ over land. Over ocean, the uncertainties of $f$ are large for low AOT $(\tau<0.15)$ but typically less than about $20 \%$ for large AOT $(\tau>0.15)$ [Kleidman et al., 2005; Remer et al., 2005]. Over land, MODIS does not provide any quantitative information about the aerosol size [Levy et al., 2010]. As a result, we use the $\tau$ and $f$ data over the ocean only. The period of 4 July 2002 to 1 June 2009 is used for consistency with the study by Tian et al. [2011].

[14] Note that we use MODIS/Aqua aerosol data rather than MODIS/Terra data even though MISR is on board Terra. One reason is that we want to be consistent with the study in Tian et al. [2011]. More importantly, MODIS/Terra 
and MISR aerosol retrievals have very little spatial overlap due to the exclusion of Sun glint regions over the ocean for MODIS. As a result, there are far fewer days on which both MODIS/Terra and MISR made observations of a given region, compared to the situation between MODIS/Aqua and MISR. Because the direct comparison between daily MODIS and MISR aerosol data serves as an essential part of this study, we chose to use MODIS/Aqua data. Nevertheless, the difference between the results based on MODIS/ Terra and those based on MODIS/Aqua is found to be negligible for our application.

[15] Data rejection has been performed on the MODIS $\tau$ and $f$ observations as discussed in Appendix A. It is noted that we applied equations (3) and (4) in a stricter way than what was originally done by Kaufman et al. [2005a, $2005 \mathrm{~b}$. Nevertheless, it should be noted that although the data rejection we applied removes a large number of suspicious observations, doing so does not in itself guarantee the accuracy of the remaining points, given that $f_{\text {dust }}, f_{\text {smoke }}$, and $f_{\text {mar }}$ are assumed constant, and $\tau_{\text {mar }}$ is estimated from an empirical formula. For the former factor, sensitivity tests are performed to examine the extent to which our results are sensitive to the variations in f values. For the latter, the deviations of the actual $\tau_{\text {mar }}$ (mainly sea salt) compared to that empirically computed will be interpreted primarily as changes in dust amount, thus affecting the accuracy of $\tau_{\text {dust }}$. However, as will be presented next, MISR can distinguish dust from sea salt based on retrieved particle shape, thus $\tau_{\text {dust }}$ derived from MISR is not subject to the ambiguity between dust and sea salt that affects Kaufman's method. In this sense the examination of MISR aerosol observations provides validation for the more extensive MODIS data set, in addition to offering actual results independent of MODIS.

\subsection{Multi-Angle Imaging SpectroRadiometer}

[16] Viewing the Earth simultaneously at nine widely spaced angles, MISR/Terra provides global coverage every 7-9 days. The variations between the reflectance acquired from a range of observation angles can be interpreted (with appropriate models) in terms of aerosol properties such as particle size, shape, and single-scattering albedo [Kahn et al., 1998, 2001; Chen et al., 2008]. In particular, MISR's sensitivity to the characteristics of the aerosol scattering phase function enables it to distinguish between the nonspherical and spherical particles, and thus provides a possible way to separate mineral dust aerosols from other aerosol components. A series of studies has explored the ability of MISR to retrieve mineral dust properties theoretically [Kahn et al., 1997, 2001; Kalashnikova et al., 2005; Kalashnikova and Kahn, 2006], the sensitivity of the theoretical results, as well as the application of nonspherical dust models for five Saharan dust field events over the Atlantic Ocean [Kalashnikova and Kahn, 2008].

[17] Assuming the mineral dust is all nonspherical and the nonspherical part of AOT is all from dust, MISR $\tau_{\text {dust }}$ can be directly computed as the nonspherical fraction of the total AOT:

$$
\tau_{\text {dust }}=\tau \times \text { frac }_{\text {nonspherical }}
$$

[18] For MISR, smoke and marine aerosols (both sea salt and sulfate aerosols) contribute to the spherical part of the total AOT. (Refer to Table 3 in Kahn et al. [2001] for more details on shape categories of different aerosol components.) If $\tau_{\text {mar }}$ is again taken as computed from equation $(5), \tau_{\text {smoke }}$ can be approximated as the difference between the total $\tau$ and $\tau_{\text {dust }}$ and $\tau_{\text {mar }}$

$$
\tau_{\text {smoke }}=\tau-\tau_{\text {dust }}-\tau_{\text {mar }}
$$

[19] However, it should be kept in mind that unlike MISR $\tau_{\text {dust }}$, the MISR $\tau_{\text {smoke }}$ derived this way, and all the MODIS particle type distinctions, are not independent observations based on actual physical constraints, and their accuracy is subject to the large uncertainties due to the empirically calculated $\tau_{\text {mar }}$.

[20] We use MISR-derived Level 3 daily $\tau$ and nonspherical fraction at $0.558 \mu \mathrm{m}$ on $0.5^{\circ} \times 0.5^{\circ}$ spatial grids during the same time period as the MODIS data. MISR $\tau$ and $\tau_{\text {dust }}$ are averaged onto $1^{\circ} \times 1^{\circ}$ grids to compare with MODIS results. A number of validation studies have shown that overall, about $70 \%$ to $75 \%$ of MISR AOT retrievals, their retrieval errors fall within 0.05 or $20 \% \times \mathrm{AOT}$, and about $50 \%$ to $55 \%$ are within 0.03 or $10 \% \times$ AOT, except at sites where mixed dust and smoke are commonly found [Kahn et al., 2010]. Particle property validation suggests that expected MISR sensitivity to the spherical versus nonspherical particles is about $20 \%$ for AOT above 0.15, and diminishes for midvisible AOT below this value [Kahn et al., 1997; Kalashnikova et al., 2005; Kalashnikova and Kahn, 2006]. Thus, we only use $\tau \geq 0.15$ to calculate $\tau_{\text {dust }}$ from equation (6). With this $\tau$ cutoff, it is found that more than $70 \%$ of the observations still remain for calculation over most of the tropical Atlantic. Note that generally, MISR $\tau$ retrievals are available about $15 \%$ of the time, except over the convectively active regions (decreased to about $10 \%$ ). Although it has never been explicitly addressed, MODIS sensitivity to particle properties, e.g., $f$, also diminishes at low AOT (implied in Figure 7 in Kahn et al. [2009]), and MISR actually has greater sensitivity at low AOT than MODIS due to the long atmospheric paths observed by its steeper-viewing cameras.

[21] Note that MISR also retrieves aerosol particle size information, thus conceptually it is possible to follow the same method utilized for MODIS to separate the total AOT into specific types in MISR. However MISR categorizes the aerosol particles into three bins: "fine" (particle radii $<0.35 \mu \mathrm{m}$ ), "medium" (radii between 0.35 and 0.7 ), and "large" (radii $>0.7 \mu \mathrm{m})$ modes, instead of two bins as "fine" vs. "coarse" in MODIS. Thus, applying Kaufman's formula to MISR would require considerable additional work, but not necessarily lead to greater insight, because similar assumptions would be required to apply the MODIS size-discrimination method to MISR. Furthermore, the different radii range for MODIS and MISR "fine" mode would make it impossible to cross-validate the $f$ values between these two data sets. Most importantly, the retrieval of $\tau_{\text {dust }}$ in MISR is based on actual aerosol physical property, thus considered to be preferable to Kaufman's method. Therefore, using MISR aerosol size information to separate different aerosol components following Kaufman's method is not only beyond the scope of current paper, but also less desirable. 

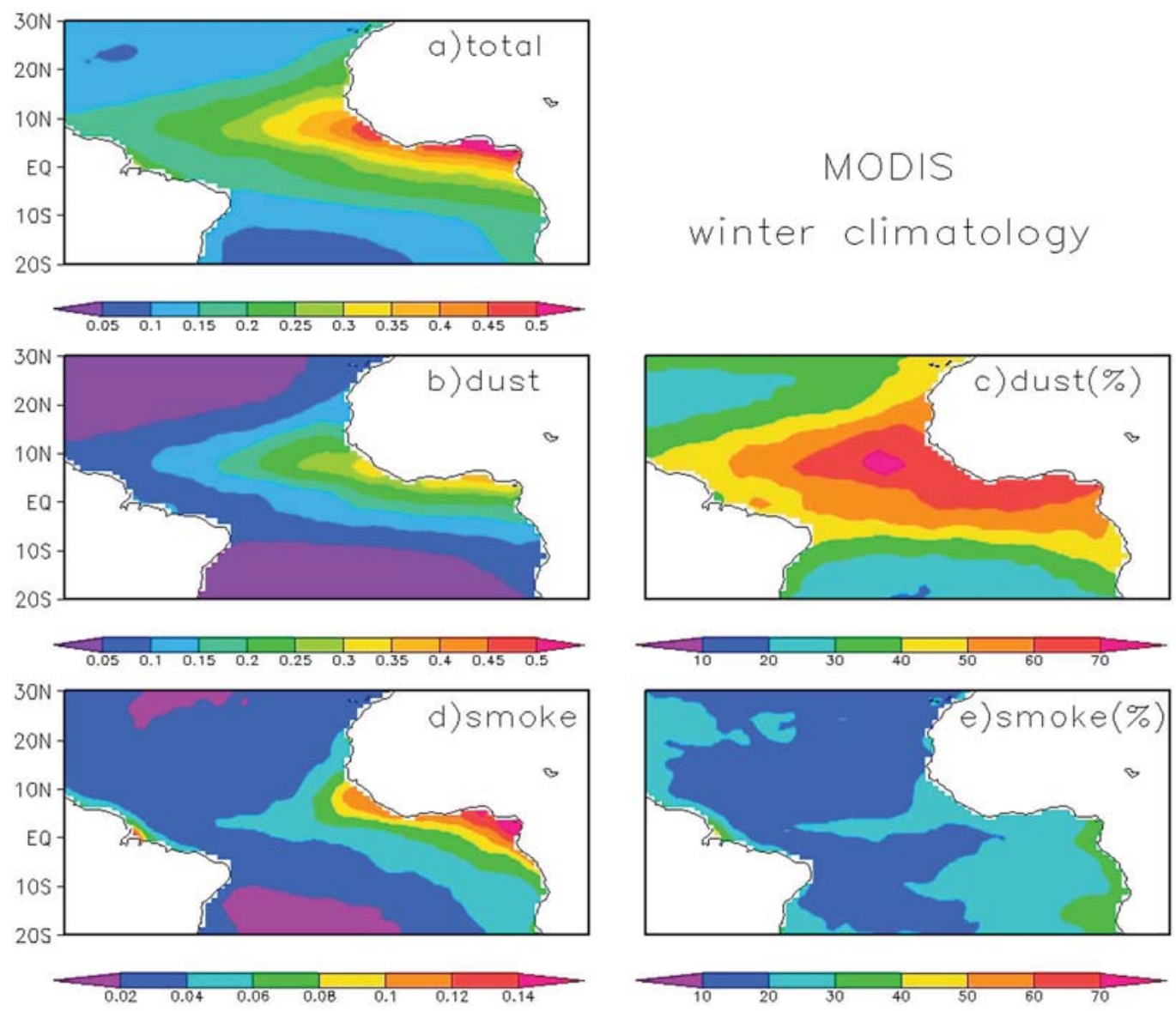

\section{winter climatology}
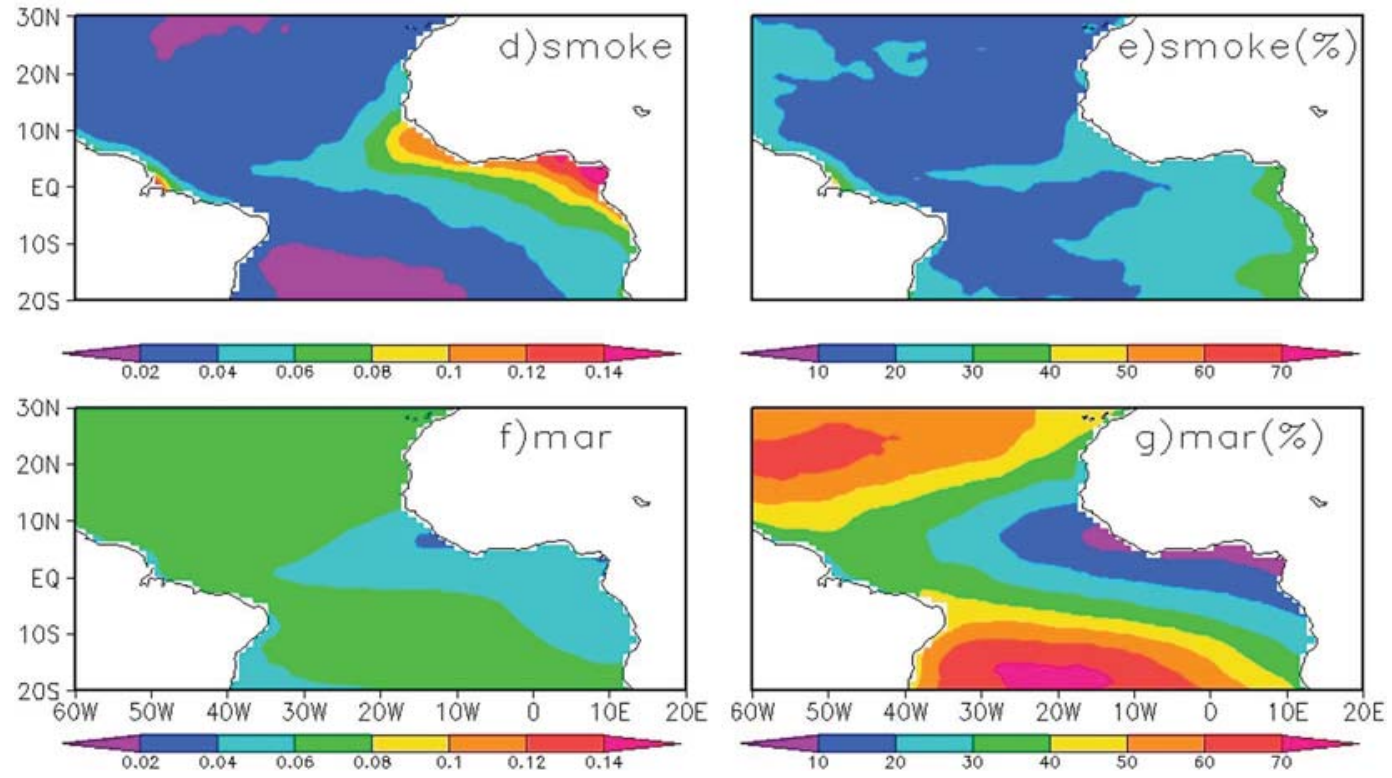

Figure 1. MODIS climatological mean (2002-2009) boreal winter (a) total $\tau$, (b) $\tau_{\text {dust }}$, (d) $\tau_{\text {smoke, and }}$ (f) $\tau_{\text {mar }}$ over the tropical Atlantic Ocean, and their percentages to $\tau$ ((c) $\tau_{\text {dust }}$, (e) $\tau_{\text {smoke }}$, and (g) $\left.\tau_{\text {mar }}\right)$. Ninepoint spatial smoothing is applied.

[22] Beside the MODIS and MISR aerosol data, $1^{\circ} \times 1^{\circ}$ precipitation from Tropical Rainfall Measurement Mission 3B42 Version 7 data set [Huffman et al., 2007] and $1.5^{\circ}$ $1.5^{\circ}$ daily horizontal winds from the ECMWF ERAInterim reanalysis [Dee et al., 2011] during the same time period are also used.

\section{Comparison of Aerosol Components Between MODIS and MISR}

[23] In this section, the AOTs of individual aerosol components over the tropical Atlantic Ocean are examined, and the MODIS and MISR results are compared. Climatological maps are examined first, to investigate how well the methods presented in section 2 capture the basic features of the longterm mean.

\subsection{Aerosol Winter Climatology}

3.1.1. Moderate Resolution Imaging Spectroradiometer [24] The MODIS winter climatological mean (November to April during 2002-2009) aerosol maps over the tropical Atlantic Ocean are shown in Figure 1. The climatological mean $\tau$ features a zonally oriented, optically thick aerosol plume centered at around $5^{\circ} \mathrm{N}-8^{\circ} \mathrm{N}$ stretching across the equatorial Atlantic Ocean. The magnitude and latitudinal extent are greatest over the eastern equatorial Atlantic with the maximum $\tau$ up to 0.5 and gradually decrease westward toward the central and western equatorial Atlantic, as expected for an aerosol plume that originates in Africa (Figure 1a). Note that due to data rejection performed in this study, Figure 1a is highly similar but not identical to the color shadings in Figure 1b in Tian et al. [2011] although they display the same quantity: the magnitude of former is 

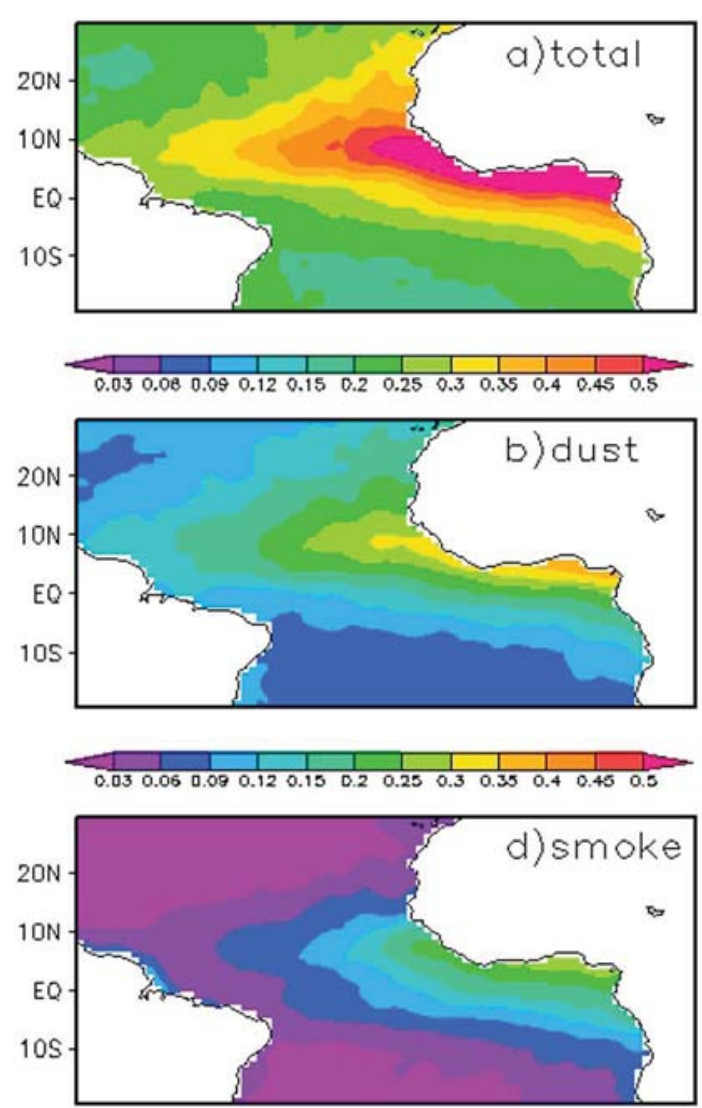

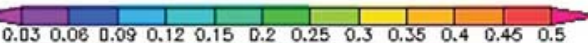

\section{MISR \\ winter climatology}
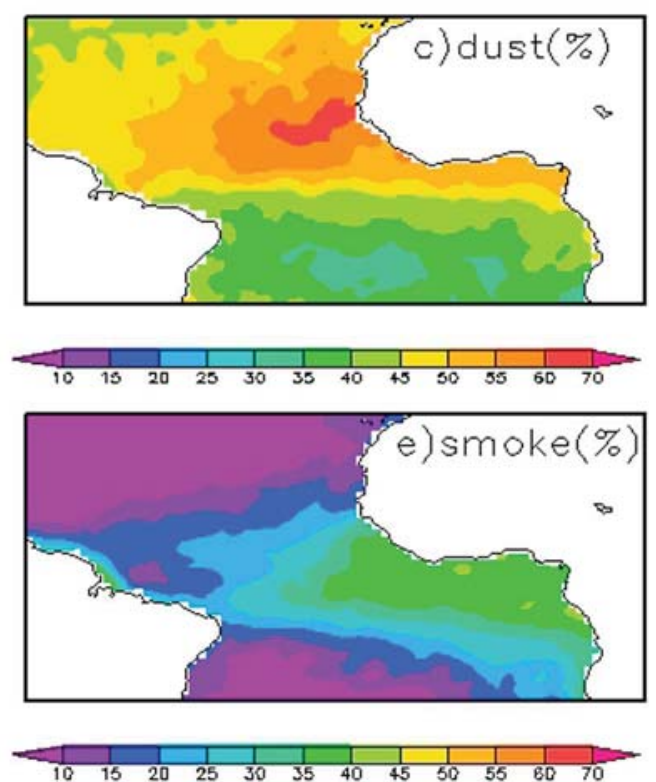

Figure 2. Same as Figures $2 \mathrm{a}-2 \mathrm{e}$ but for MISR, and only cases with MISR $\tau \geq 0.15$ used.

about $80 \%$ of the latter over the equatorial region. Nevertheless, they have a spatial correlation of 0.98 .

[25] The spatial pattern of climatological $\tau_{\text {dust }}$ closely resembles the $\tau$ pattern, with maximum $\tau_{\text {dust }}$ (about 0.35 ) found along the west coast of Africa, and a gradual decrease toward the central and western equatorial Atlantic (Figure 1b). Over the equatorial Atlantic Ocean, where aerosol loading is high $(\tau>0.15)$, dust is the dominant aerosol component, contributing more than $50 \%$, and as much as $75 \%$, to $\tau$ (Figure 1c).

[26] Compared to $\tau_{\text {dust }}, \tau_{\text {smoke }}$ is significantly weaker. Plumes of fine-mode-dominant aerosol are found originating from the African (biomass burning smoke) as well as the South American continents (smoke or air pollution) (Figure 1d). A contribution of more than $20 \%$ to total $\tau$ is found over the eastern tropical Atlantic, whereas the contribution is less than $20 \%$ over the western part (Figure 1e). Figure 1f shows that $\tau_{\text {mar }}$ is very small (about 0.04 ) over the Atlantic intertropical convergence zone and the west coast of Africa because of the weak trade winds. Over the clean subtropical Atlantic, marine aerosol is the dominant component $(>50 \%)$ due to a lack of dust and smoke aerosols over these regions.

[27] These results indicate that the major aerosol plume over the equatorial Atlantic Ocean in Figure 1a is the dust originating in the Sahara desert and the Sahel region, with some contribution from biomass burning smoke originating in the
Sahel and African savanna. These aerosol distributions are generally consistent with previous observational results [e.g., Husar et al., 1997; Kaufman et al., 2005a; Huang et al., 2010], lending some confidence in estimating dust and smoke aerosols based on equations (3) and (4).

\subsubsection{Multi-Angle Imaging SpectroRadiometer}

[28] Multi-angle Imaging SpectroRadiometer winter climatologies of $\tau, \tau_{\text {dust }}$, and $\tau_{\text {smoke }}$ are shown in Figure 2 . Recall that for these results only cases with $\tau \geq 0.15$ are used due to the fact that sensitivity to shape diminishes when aerosol concentration is low. Different data rejection is applied to MODIS $\tau$, as discussed in the Appendix A, thus, we do not expect Figure $2 \mathrm{a}$ to be the same as Figure 1a. Nevertheless, we do find that they have highly consistent spatial patterns and comparable magnitudes. The climatological MISR $\tau_{\text {dust }}$ map (Figure $2 b$ ) is also very similar to the MODIS $\tau_{\text {dust }}$ (Figure $1 \mathrm{~b}$ ). The MISR $\tau$ and $\tau_{\text {dust }}$ are slightly larger than the MODIS counterparts partly due to MISR's exclusion of low aerosol cases, but more important reasons will be addressed in section 3.2. It is seen that MISR $\tau_{\text {dust }}$ contributes more than $40 \%$, up to more than $60 \%$, to the total $\tau$ for cases with $\tau \geq 0.15$, further confirming that dust is the dominant aerosol component over the equatorial Atlantic Ocean (Figure 2c). It is also noted that MISR has $10 \%$ to $15 \%$ lower dust fraction over the equatorial Atlantic. Again, this difference could be partly attributed to the $\tau$ cutoff applied to MISR, but more importantly could result from 

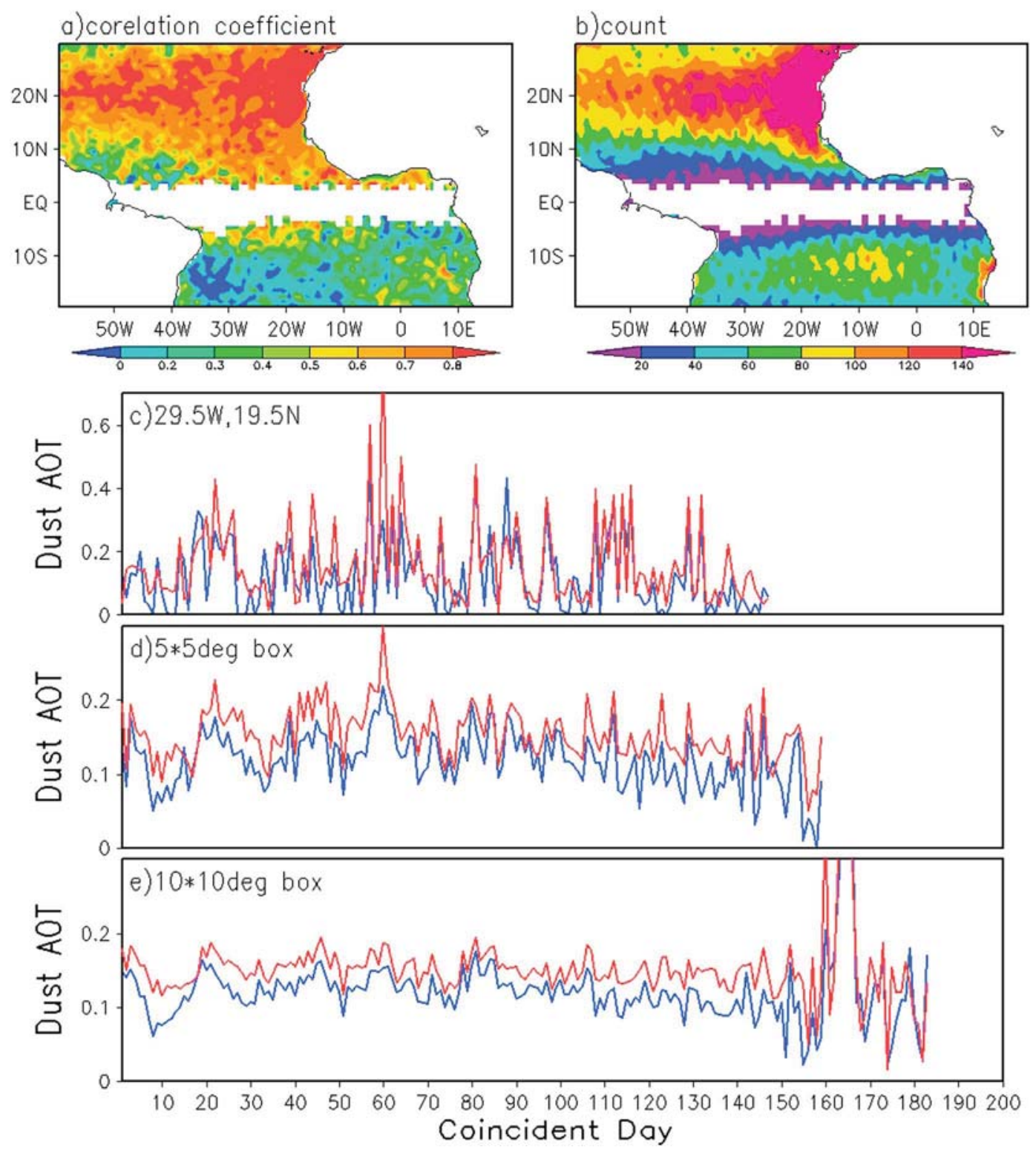

Figure 3. (a) Correlation coefficients between coincident MODIS $\tau_{\text {dust }}$ and MISR $\tau_{\text {dust }}$ during 20022009 over the tropical Atlantic and (b) the number of coincident days. Time series of MODIS (blue) and MISR (red) $\tau_{\text {dust }}$ as the function of the coincident day (c) at the point of $29.5^{\circ} \mathrm{W}, 19.5^{\circ} \mathrm{N}$, averaged on the (d) $5^{\circ} \times 5^{\circ}$ and (e) $10^{\circ} \times 10^{\circ}$ boxes centered at $29.5^{\circ} \mathrm{W}, 19.5^{\circ} \mathrm{N}$.

both uncertainties involved in the derivation of MODIS and MISR $\tau_{\text {dust }}$, especially in MODIS, given the assumptions used. We return to this point in section 3.2. The climatological MISR $\tau_{\text {smoke }}$ has a $10 \%$ larger contribution to total $\tau$ than MODIS $\tau_{\text {smoke }}$ over the equatorial Atlantic (Figures 2d and 2e compared to Figures 1d and 1e).

[29] The overall consistency between the MODIS and MISR aerosol climatology, representing two independent satellite data sets and methods used to derive the dust and smoke aerosols over the tropical Atlantic Ocean, gives us some confidence in applying the results. However, the consistency in climatology does not guarantee their consistency on shorter time scales, for example, on the intraseasonal time scale of importance here. Therefore, in the next subsection we directly compare the coincident daily MODIS and MISR $\tau_{\text {dust }}$ over the tropical Atlantic Ocean.

\subsection{Comparison of Coincident MODIS and MISR Dust Aerosols}

[30] The correlation between the daily MODIS and MISR $\tau_{\text {dust }}$ for all their coincident days (minimum of 5) during 2002-2009 is calculated over the tropical Atlantic. Here the term "coincident" simply means the MODIS and MISR observations fall within a same grid box and on a same day, which is less strict than the usual definition used by the satellite community. We use the entire years for 2002-2009 instead of winters only to obtain as many coincident days as possible. [31] Overall, the MODIS and MISR $\tau_{\text {dust }}$ are well correlated in the regions of primary interest here, where dust dominates. The correlation is systematically higher in the north Atlantic region (typically around 0.7 or larger) than in the south Atlantic where the correlation is typically less than 

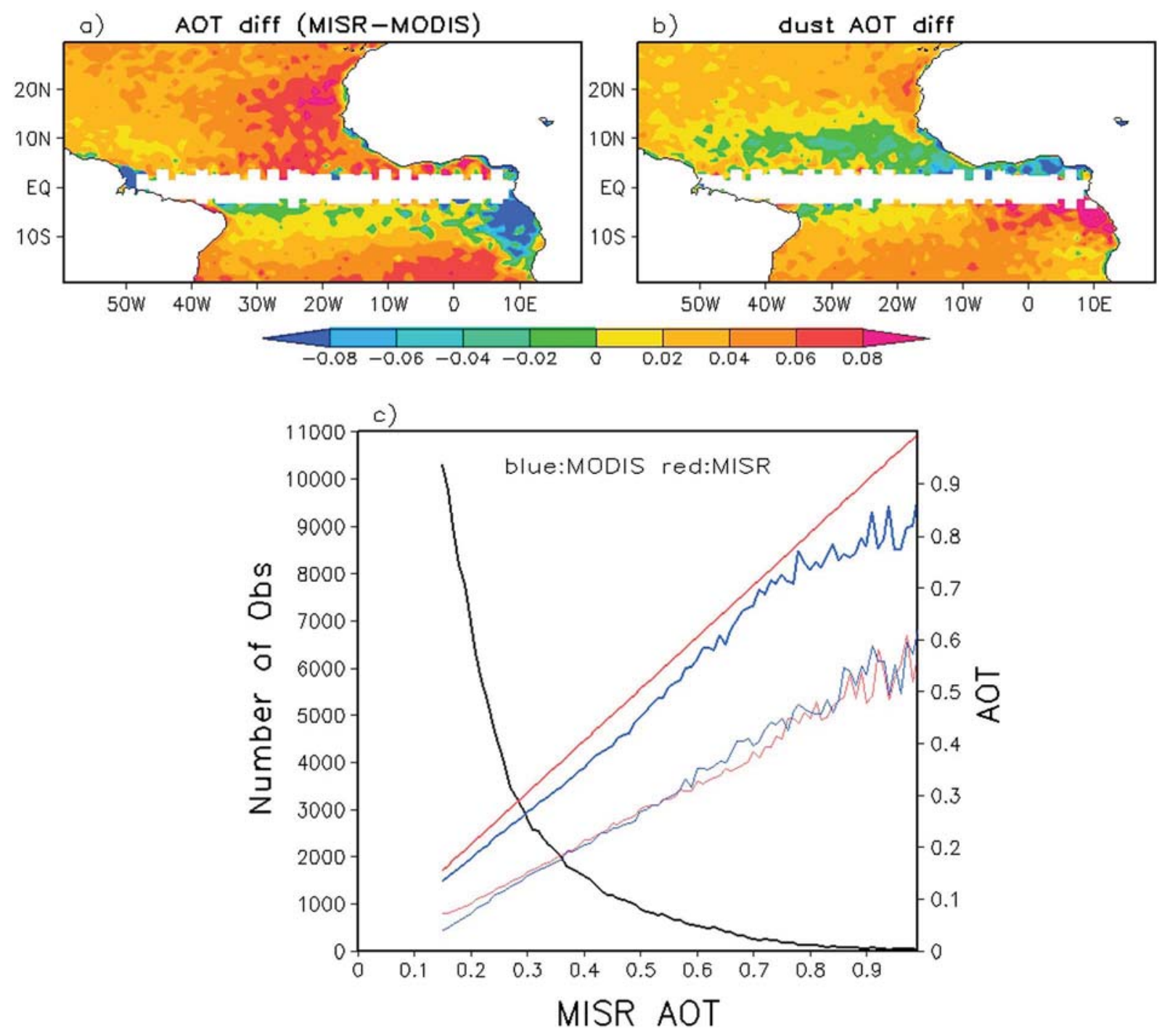

Figure 4. (a) MISR and MODIS $\tau$ difference averaged over coincident days during 2002-2009. (b) Same as Figure $4 \mathrm{a}$, but for $\tau_{\text {dust }}$. (c) Number of coincident MODIS and MISR observations (black line), averaged MODIS $\tau$ (thick blue line), MISR $\tau$ (thick red line), MODIS $\tau_{\text {dust }}$ (thin blue line), and MISR $\tau_{\text {dust }}$ (thin red line) over $20^{\circ} \mathrm{S}-30^{\circ} \mathrm{N}, 60^{\circ} \mathrm{W}-20^{\circ} \mathrm{E}$ during $2002-2009$ as a function of binned MISR $\tau$ (binned by every 0.01 ).

0.5 , with quite a few spots less than 0.2 , or even negative (Figure 3a). Note that there are more coincident days over the north Atlantic (Figure 3b). Furthermore, the correlation is higher when it is closer to the African continent, and decreases gradually as the dust is transported away from the source region. These results suggest that MODIS and MISR $\tau_{\text {dust }}$ agree with each other quite well over heavy dust load regions, whereas they are less consistent over the regions with less frequent dust occurrence or small dust aerosol concentration.

[32] Figure 3a shows that overall, the MODIS and MISR $\tau_{\text {dust }}$ are highly correlated; however the correlation coefficient does not provide information on the $\tau_{\text {dust }}$ magnitude. Therefore, the time series of MODIS and MISR $\tau_{\text {dust }}$ as a function of their coincident days at a representative grid point $\left(29.5^{\circ} \mathrm{W}\right.$, $19.5^{\circ} \mathrm{N}$ ), as well as averaged within the $5^{\circ} \times 5^{\circ}$ and $10^{\circ} \times 10^{\circ}$ grid boxes centered at this point, are shown (Figures 3c-3e). Again it is found that the MODIS and MISR $\tau_{\text {dust }}$ are highly correlated on a daily basis, and it also reveals that $\tau_{\text {dust }}$ is systematically greater for MISR than MODIS.
[33] Multi-angle Imaging SpectroRadiometer $\tau_{\text {dust }}$ is larger than MODIS $\tau_{\text {dust }}$ over most of the tropical Atlantic when averaged for coincident days (about 0.03 larger averaged over the basin), except in some regions north of the equator (Figure 4b). This difference can be traced to the difference between MISR and MODIS total AOT (Figure 4a). Over almost the entire tropical Atlantic, coincident MISR AOTs are systematically larger than the MODIS ones (up to 0.08 , and about 0.04 when averaged for the Atlantic basin). This is consistent with previous studies in which MISR AOT is found to be generally larger than MODIS AOT over water [e.g., Abdou et al., 2005; Kahn et al., 2010]. Further examination of coincident MODIS and MISR $\tau$ and $\tau_{\text {dust }}$ binned against the MISR $\tau$ reveals that larger MISR $\tau$ is found for the entire $\tau$ spectrum, whereas MISR $\tau_{\text {dust }}$ is larger when the aerosol concentration is relatively low (Figure 4c). Note that lower aerosol concentrations are overwhelmingly more frequent (black line in Figure $4 \mathrm{c}$ ), thus the averaged MISR $\tau_{\text {dust }}$ is larger than the averaged MODIS $\tau_{\text {dust }}$. As seen above, the 

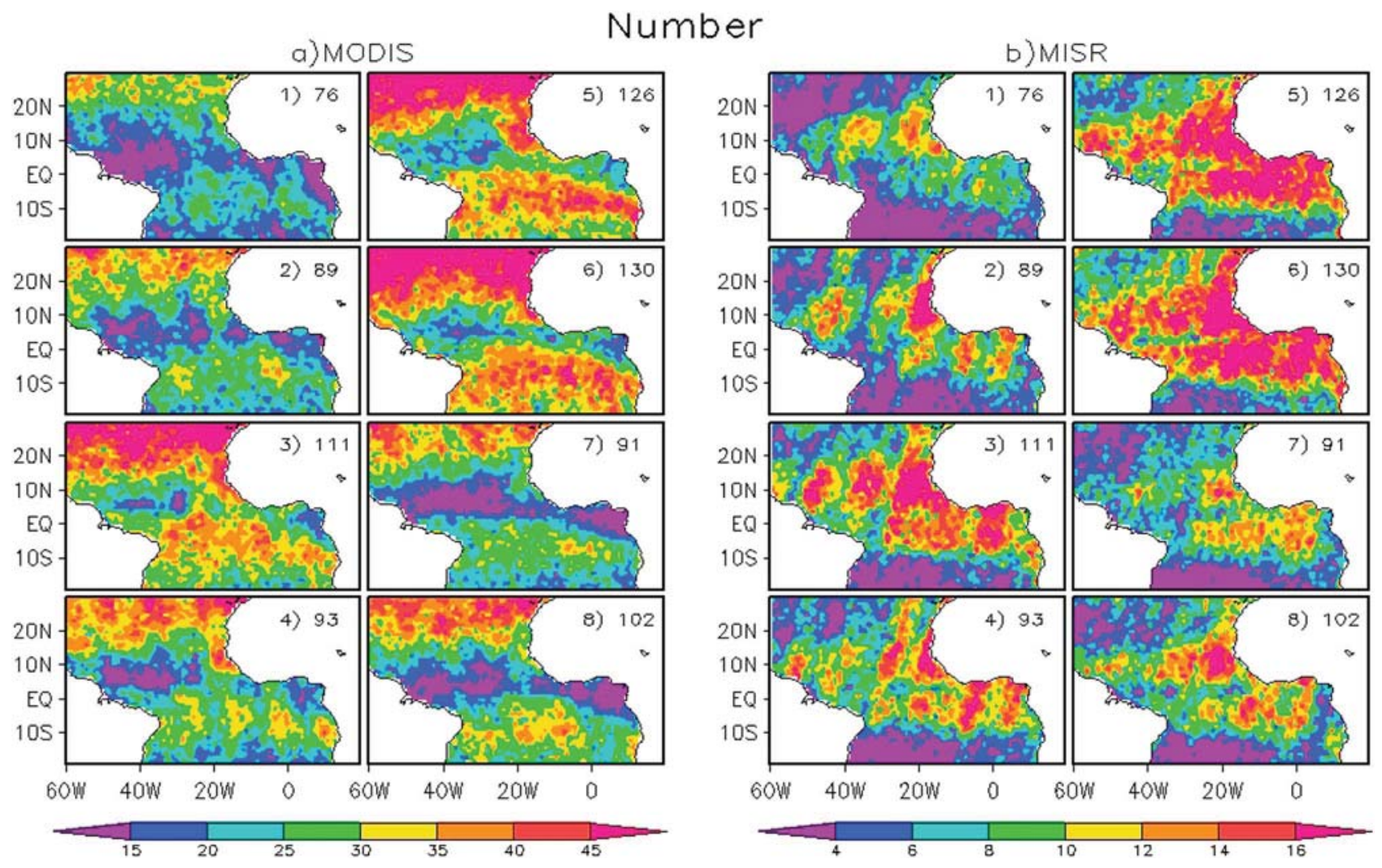

Figure 5. The number of strong MJO events used for MJO composite for each phase of the MJO cycle for (a) MODIS and (b) MISR during the 2002-2009 boreal winters. The total number of strong MJO events during this period is indicated at the right upper corner of each panel.

$\tau_{\text {dust }}$ difference between MODIS and MISR can be traced to the $\tau$ difference between them. However, this is not the only reason, as, unlike MISR $\tau$, MISR $\tau_{\text {dust }}$ is not systematically larger than MODIS $\tau_{\text {dust }}$. The uncertainties involved in the derivation of both MODIS and MISR $\tau_{\text {dust }}$ inevitably contribute to their differences too. However it should be noted that although both methods have limitations, MISR dust discrimination is based on actual retrieved particle shape information, whereas the accuracy of MODIS $\tau_{\text {dust }}$ is subject to the use of constant $f$ values and empirically calculated $\tau_{\text {mar. }}$. Despite more physically robust separation of $\tau_{\text {dust }}$ from $\tau$ in MISR, it has much less frequent sampling compared to MODIS, thus it is necessary to examine both data sets. Results based on these two complementary satellite data sets will provide more solid insight to the characteristics of the MJO-related dust and to some extent smoke variations.

\section{MJO-Related Atlantic Dust and Smoke AOT Anomalies}

\subsection{MJO Analysis Methodology}

[34] For the MJO analysis and composite procedure, we use the multivariate empirical orthogonal function method introduced by Wheeler and Hendon [2004] and adopted widely by the MJO community [e.g., Waliser et al., 2009]. In this method, eight distinct phases of the MJO cycle are determined by a pair of Real-time Multivariate MJO (RMM) index (RMM1 and RMM2) [Wheeler and Hendon, 2004]. Typically, when enhanced MJO convection is located over the equatorial Indian Ocean (phase 1 and 2) and western hemisphere (phase 8), persistent low-level westerly anomalies and enhanced precipitation are found over the equatorial Atlantic, whereas the reverse conditions are found when the MJO convection is located over the maritime continent (phase 4) and western Pacific (phase 5 and 6).

[35] In this study, first, the intraseasonal anomalies of daily AOT are obtained by removing the climatologicalmean seasonal cycle and filtering via a 30-90 day band pass filter. Then, a composite MJO cycle is calculated by averaging the daily anomalies that occur within each phase of the MJO cycle. Only days having strong MJO activity $\left(\mathrm{RMM}^{2}+\mathrm{RMM}^{2}>=1\right)$ are considered for the MJO cycle composite.

\subsection{MJO Composites of Dust and Smoke Anomalies}

[36] Figure 5 shows the number of strong MJO days $\left(\mathrm{RMM}^{2}+\mathrm{RMM}^{2}>=1\right)$ used for the eight-phase MJO cycle composite for both MODIS and MISR during 2002-2009 boreal winters. The total number of strong MJO events during this period is also shown in the upper right corner of each panel. For both instruments, the number of strong MJO events used for the composite is much less than the actual number of total events because of satellite retrieval sampling issues and the data rejection applied. Generally, the number of MODIS events ranges from about 10 to 45, about as three times more than MISR, due to the much wider MODIS swath.

[37] The eight-phase MJO composite maps of MODIS total $\tau, \tau_{\text {dust }}$, and $\tau_{\text {smoke }}$ anomalies are shown in Figures $6 \mathrm{a}$, $7 \mathrm{a}$, and $8 \mathrm{a}$, respectively. The MISR counterparts will be 
a) MODIS
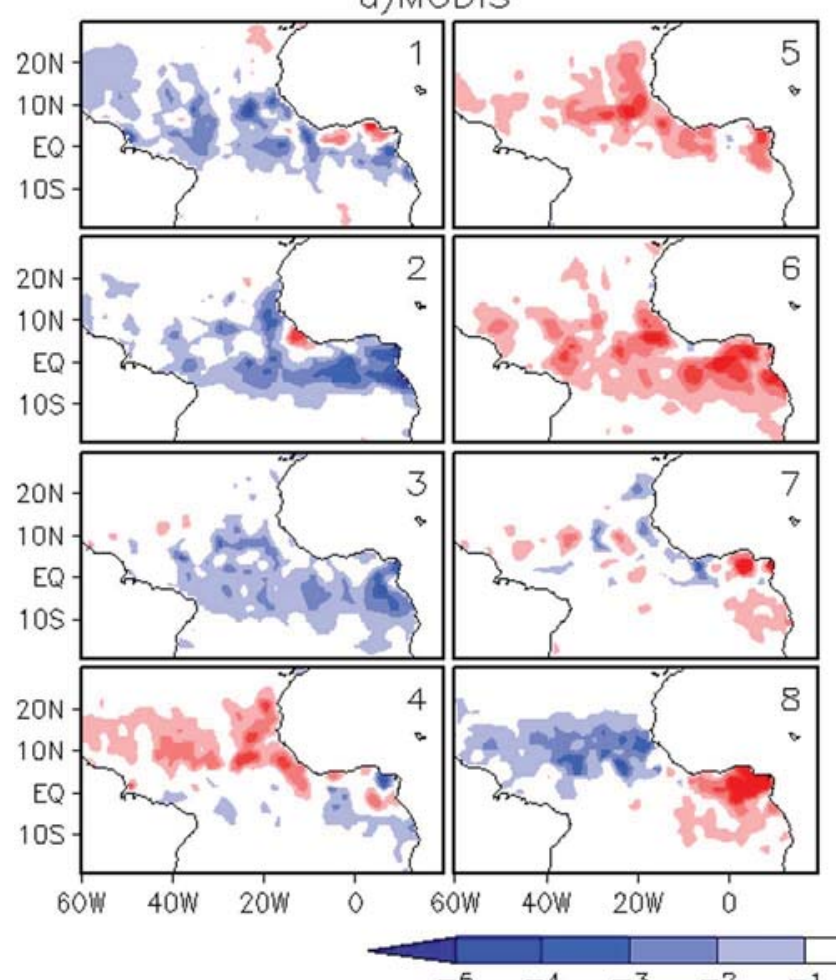

total AOT
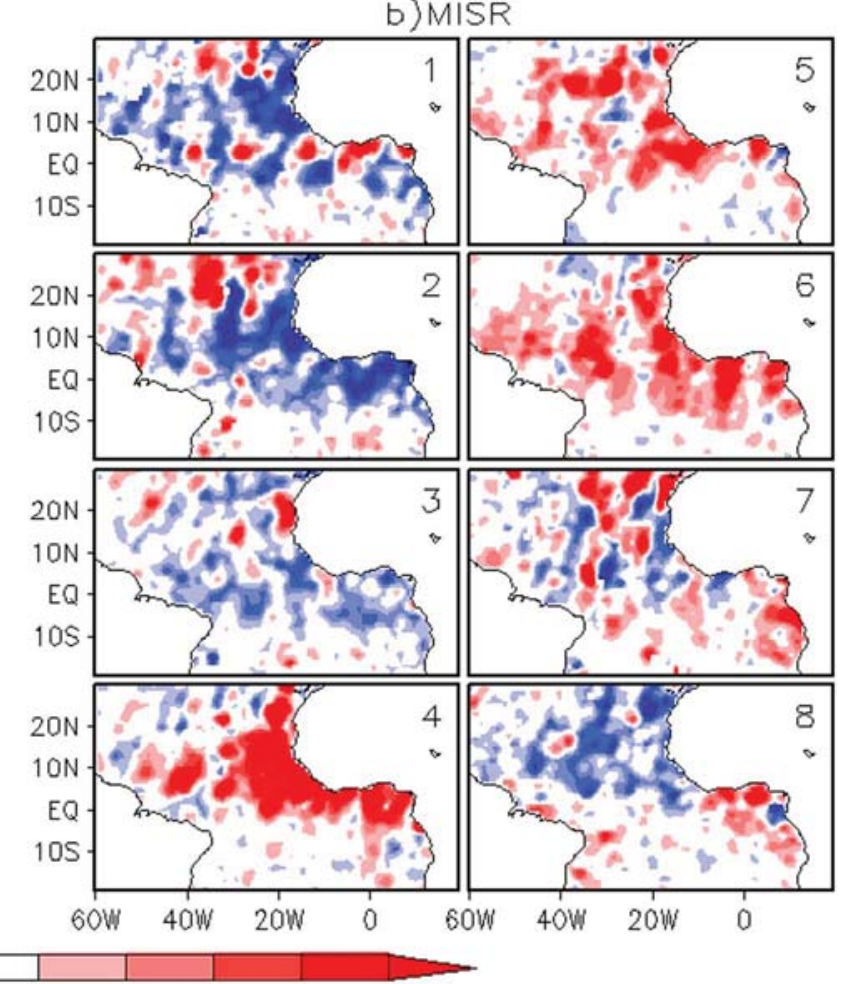

Figure 6. MJO composite maps of total $\tau$ anomalies (multiplied by 100) for (a) MODIS and (b) MISR over the tropical Atlantic Ocean. Nine-point spatial smoothing is applied.

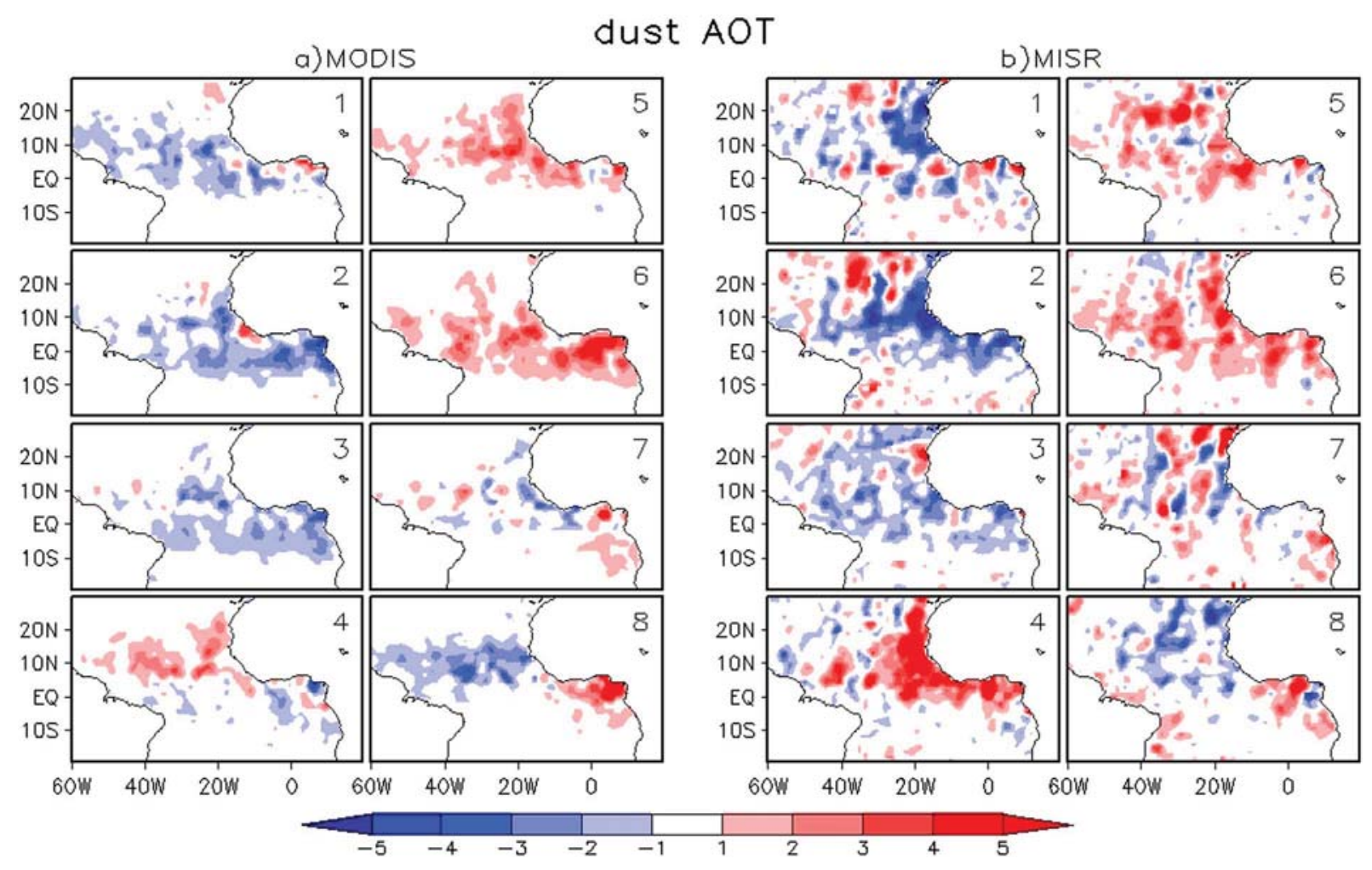

Figure 7. Same as Figure 6, but for $\tau_{\text {dust }}$. 


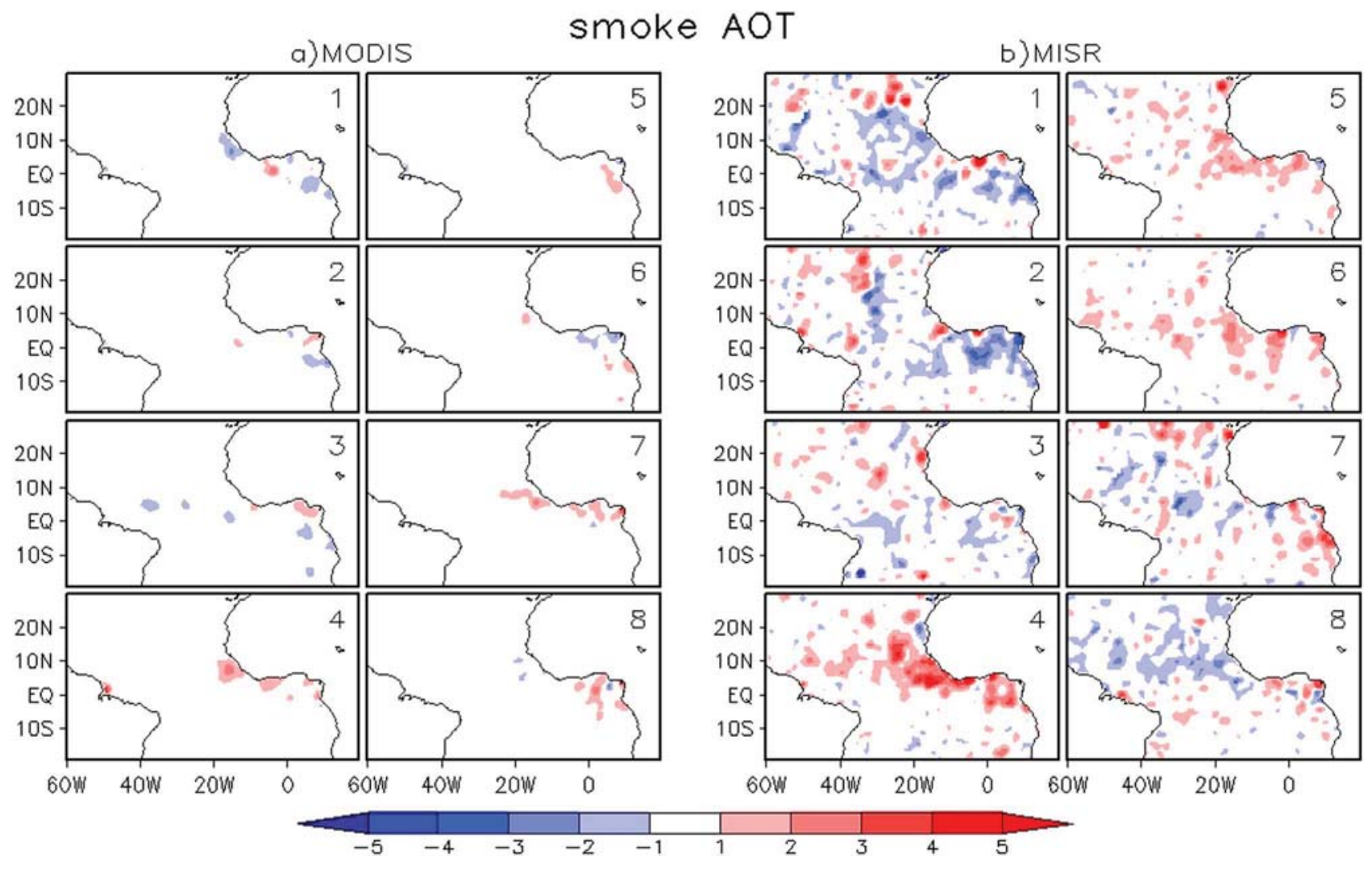

Figure 8. Same as Figure 6 , but for $\tau_{\text {smoke }}$.

discussed and compared with MODIS results later. Comparing Figures $6 \mathrm{a}$ and $7 \mathrm{a}$, MODIS $\tau$ and $\tau_{\text {dust }}$ have very similar temporal evolution and spatial patterns, except that $\tau_{\text {dust }}$ anomalies are slightly smaller. The spatial correlation between $\tau$ and $\tau_{\text {dust }}$ anomalies for eight MJO phases is 0.89 . For both $\tau$ and $\tau_{\text {dust }}$, strong negative anomalies (as large as about -0.04) are found over the entire equatorial Atlantic for MJO phases 1, 2, 3, and 8. In contrast, strong positive anomalies (up to 0.04 ) are found over the equatorial Atlantic for MJO phases 5-6. For MJO phase 4, strong positive anomalies occur to the north of the equator, whereas negative $\tau$ anomalies are found to the south. The converse is true for the MJO phase 7. The MJO composite maps of total $\tau$ greatly resemble those shown by Tian et al. [2011], with spatial correlation 0.52 (significant at the $99.9 \%$ level), and have very similar magnitudes. This resemblance suggests that the MJO-related total AOT anomaly patterns are robust and not sensitive to the data sampling (fewer but more carefully filtered samples are used in this study). The MJO-related $\tau_{\text {smoke }}$ anomalies in MODIS are very weak, rarely exceeding 0.01 (Figure 8a). The spatial correlation between $\tau_{\text {smoke }}$ and $\tau$ anomalies is only about 0.21 . The MJO composite maps of $\tau_{\text {mar }}$ anomalies are not shown because $\tau_{\mathrm{mar}}$ is linearly dependent on the surface wind speed, thus the MJO-related $\tau_{\text {mar }}$ anomaly pattern in fact reflects the wind anomalies associated with the MJO, which were examined in Tian et al. [2011]. Furthermore, it is found that the magnitudes of the $\tau_{\operatorname{mar}}$ anomalies are negligible: the strongest negative/positive anomalies are about $-0.004 / 0.004$ (figure not shown).

[38] The eight-phase MJO composite maps of MISR total $\tau, \tau_{\text {dust }}$, and $\tau_{\text {smoke }}$ anomalies are shown in Figures $6 \mathrm{~b}, 7 \mathrm{~b}$, and $8 \mathrm{~b}$. Again, it is found that the $\tau_{\text {dust }}$ anomalies are significantly larger than the $\tau_{\text {smoke }}$ anomalies. The $\tau_{\text {dust }}$ anomalies have very similar patterns to those of total $\tau$, with slightly smaller magnitude, whereas the $\tau_{\text {smoke }}$ anomalies are small and noisy. Further comparison between the MISR and MODIS $\tau$ and $\tau_{\text {dust }}$ results (Figures 6 and 7) indicates that overall they exhibit very similar temporal evolution and anomaly patterns despite the systematically larger MISR anomalies compared to those of MODIS, which is likely the outcome of the systematically larger MISR $\tau$ and $\tau_{\text {dust }}$ retrievals compared to MODIS over the tropical Atlantic Ocean, and possibly more robust dust identification for MISR, as discussed earlier. The rejection of all $\tau<0.15$ data in MISR could also contribute to the above difference; however, MISR $\tau$ anomalies with no data rejection do not show evident differences (Figure not shown). Besides the magnitude difference, MISR $\tau$ and $\tau_{\text {dust }}$ anomalies are also noisier than the MODIS anomalies due to lower sampling. Furthermore, although MISR $\tau_{\text {smoke }}$ anomalies are small too, they are notably stronger than the MODIS $\tau_{\text {smoke }}$ anomalies. Nevertheless, the consistency between the MODIS and MISR results shown in Figures 6-8 demonstrate that dust is the dominant aerosol component on the intraseasonal time scale, and the MJO-related dust anomalies are robust, as seen from two independent sets of satellite observations having different strengths and limitations.

\subsection{Sensitivity of MODIS Results}

[39] The Kaufman et al. method for computing $\tau_{\text {dust }}$ and $\tau_{\text {smoke }}$ using MODIS $\tau$ and $\mathrm{f}$ based on equations (3) and (4) is straightforward; however, large uncertainties in the computed $\tau_{\text {dust }}$ and $\tau_{\text {smoke }}$ are expected for at least several 


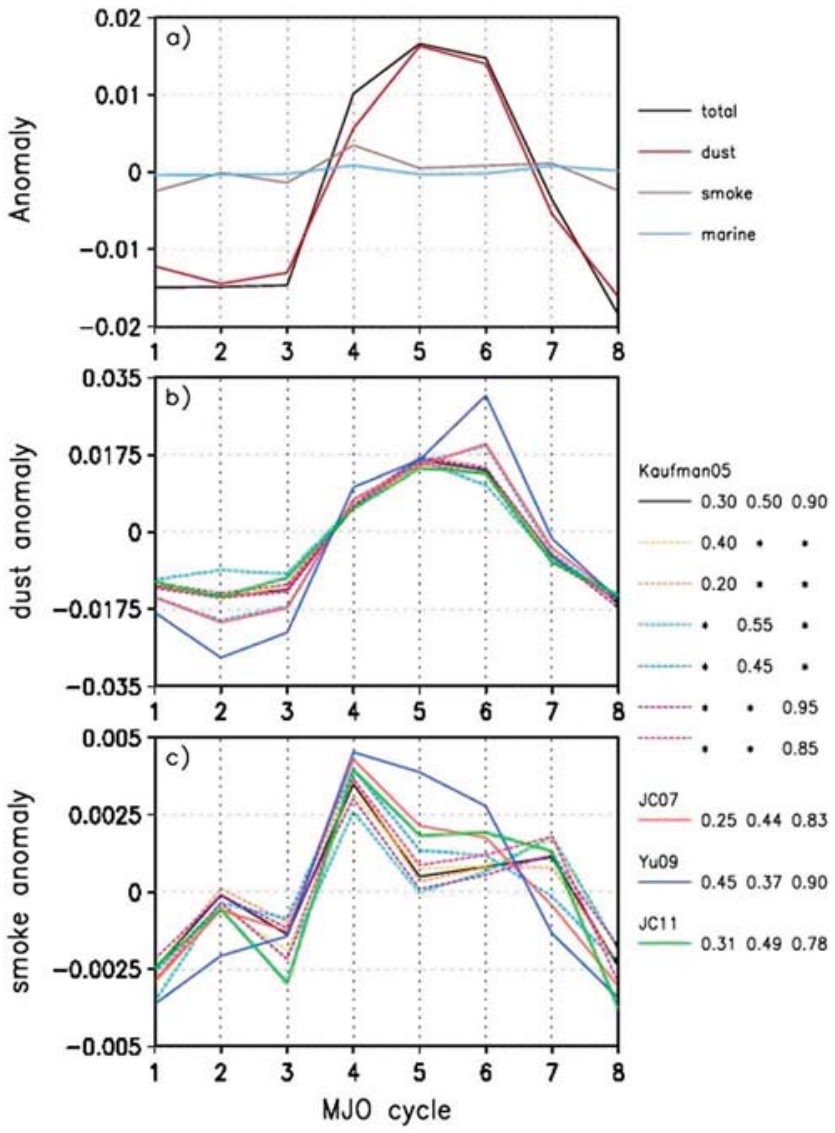

Figure 9. (a) The composite MJO cycle of MODIS total $\tau$, $\tau_{\text {dust }}, \tau_{\text {smoke }}$, and $\tau_{\text {mar }}$ anomalies averaged over $30^{\circ} \mathrm{W}-5^{\circ} \mathrm{W}$, EQ $-15^{\circ} \mathrm{N}$ for the control case. (b and c) The MJO cycle of MODIS $\tau_{\text {dust }}$ and $\tau_{\text {smoke }}$ anomalies based on the control case (black) and nine sensitivity test cases (color) with $f_{\text {mar }}, f_{\text {dust }}$, and $f_{\text {smoke }}$ of each case indicated in the legend.

reasons: the uncertainties in the MODIS $\tau$ and $f$ retrievals, the uncertainties in empirically computed $\tau_{\text {mar, }}$, and most critically, the uncertainties resulting from assuming constant $f_{\text {mar }}, f_{\text {dust }}$, and $f_{\text {smoke. }}$ In this subsection, we examine the sensitivity of our results to the $f$ values. We first perturb the f values used in this study (see section 2.1, also denoted as the control case) by increasing/decreasing one of them at a time by its uncertainty range while keeping the other two unchanged. These sensitivity test cases are denoted group 1. We then test using f values derived by three other studies [Jones and Christopher, 2007, 2011; Yu et al., 2009], which are denoted group 2. These studies attempted to calibrate Kaufman's technique, and they rederived the $f$ values using either updated MODIS data sets, or aerosol observations from other satellite data sets, or using the GOCART (Goddard Chemistry Aerosol Radiation and Transport) model to locate regions where a single aerosol component dominates. The f values they obtained are generally consistent with what is used in the current study: $f_{\text {mar }}, f_{\text {dust }}$, and $f_{\text {smoke }}$ are $0.25,0.44$, and 0.83 , respectively from the study by Jones and Christopher [2007], 0.31, 0.49, and 0.78 from their 2011 study, and $0.45,0.37$, and 0.90 from $Y u$ et al. [2009]. $f$ values do vary spatially, and these studies find that they vary considerably depending on region and season.
[40] To facilitate quantitative comparison between the sensitivity tests and the control case, we average the composite aerosol anomalies in each MJO phase over a representative region $\left(30^{\circ} \mathrm{W}-15^{\circ} \mathrm{W}, \mathrm{EQ}-15^{\circ} \mathrm{N}\right)$ where the aerosol shows strong intraseasonal variations. First, the MJO cycles of the $\tau, \tau_{\text {dust }}, \tau_{\text {smoke }}$, and $\tau_{\text {mar }}$ anomalies based on the control case (see Figures 6a, 7a, and 8a for $\tau$, $\tau_{\text {dust }}$, and $\tau_{\text {smoke }}$ anomalies) are shown in Figure 9a. It is found that the magnitude of $\tau_{\text {dust }}$ anomalies averaged over this region is as large as that of $\tau$ anomalies, whereas $\tau_{\text {smoke }}$ and $\tau_{\text {mar }}$ have very small magnitudes. Sensitivity test results for $\tau_{\text {dust }}$ and $\tau_{\text {smoke }}$ are shown in Figures $9 \mathrm{~b}$ and $9 \mathrm{c}$, respectively. For $\tau_{\text {dust }}$, overall, the colored lines (nine sensitivity tests) cluster around the solid black curve (control case), and the MJO cycles of $\tau_{\text {dust }}$ anomalies based on different sensitivity tests show a coherent evolution. This suggests that the MJO associated $\tau_{\text {dust }}$ anomalies over the tropical Atlantic are quite robust despite the uncertainties in using constant $f$ values. Nevertheless, the lines spread in some phases. The result based on $Y u$ et al. [2009] is most different from the other cases, probably because the $f$ values in the other studies follow the sequence $f_{\text {mar }}<f_{\text {dust }}<f_{\text {smoke }}$ despite the deviations, whereas the order of $f_{\text {mar }}$ and $f_{\text {dust }}$ is reversed in the $Y u$ et al. [2009] study, i.e., the size distribution for maritime aerosol is assumed by $Y u$ et al. [2009] to contain a larger AOT fraction in the fine mode than that for dust. The spread in group 2 is naturally larger than that in group 1 . Furthermore, the $\tau_{\text {dust }}$ anomalies are more sensitive to $f_{\text {dust }}$, as indicated by the larger deviations of the dashed cyan and blue curves relative to the control case in phases 2,3 , and 6 .

[41] The spread of $\tau_{\text {smoke }}$ anomalies is quite large compared to their magnitude (Figure 9c). Thus, given the large uncertainties involved in the $\tau_{\text {smoke }}$ derivations and the small and noisy $\tau_{\text {smoke }}$ anomalies found in Figure 8, the numbers shown in Figure 9c should be more regarded as giving the signs of the MJO-related anomalies in each phase than the precise quantification of the anomalies. Nevertheless, the overall MJO cycle of $\tau_{\text {smoke }}$ anomalies is consistent among the different cases.

\subsection{Modulation of Dust and Smoke Anomalies by the MJO}

[42] The MJO is characterized by eastward propagation of enhanced or suppressed zonal wind and precipitation anomalies. Over the tropical Atlantic, low-level wind and precipitation are two critical parameters that lead to aerosol variations through their influence on aerosol emission, transport, and deposition. Tian et al. [2011] examined the lag-correlation between the total $\tau$ anomalies and the lowtroposphere zonal wind and precipitation anomalies related to the MJO. They found that the MJO modulates the tropical Atlantic aerosol primarily through the zonal wind, which can last as long as one MJO phase. The precipitation also exhibits some modulation on the aerosol, but the correlation is much weaker compared to the wind impact. In this section, we further examine the modulation of the MJO of dust and smoke aerosols through the lower-tropospheric zonal wind and precipitation.

[43] Linear lag correlation between the MODIS $\tau_{\text {dust }}$ anomalies (Figure 7a) and the low-troposphere zonal wind and precipitation anomalies [Tian et al., 2011, Figures 8 and 6] for the composite $\mathrm{MJO}$ cycle over the tropical Atlantic region is 


\section{point to point correlation}

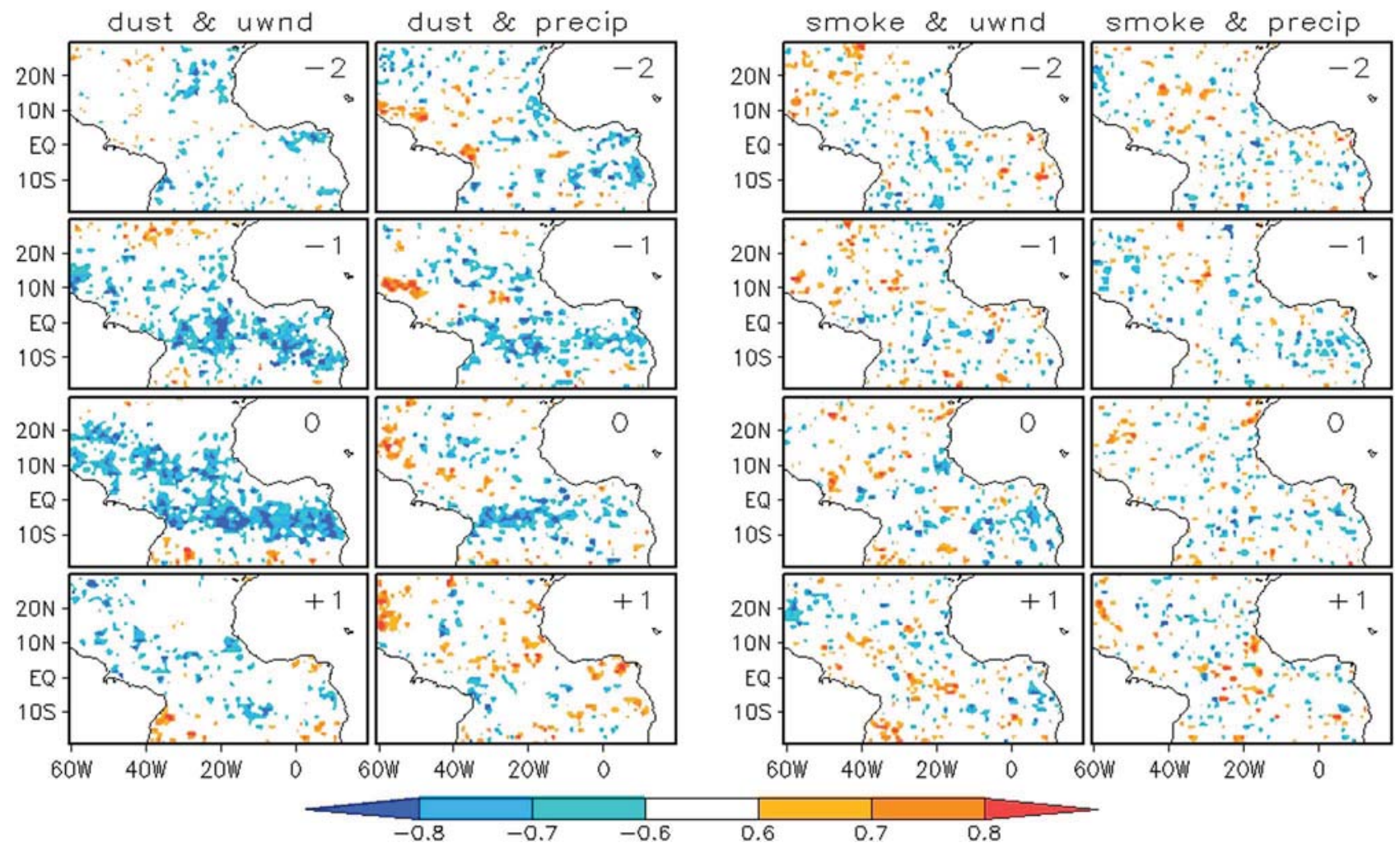

Figure 10. Linear lag correlation coefficient between the MODIS $\tau_{\text {dust }}$ anomalies and low-troposphere zonal wind anomalies (first column), $\tau_{\text {dust }}$ anomalies and precipitation anomalies (second column) for the composite MJO cycle over the tropical Atlantic region; similar but for $\tau_{\text {smoke }}$ are in the right two columns. Negative lags means the wind or precipitation anomalies lead aerosol anomalies by a certain MJO phase. Only correlation coefficients above $90 \%$ confidence limit are shown.

shown in the first two columns of Figure 10. It is found that the dust anomalies are strongly and negatively correlated with the wind anomalies over most of the tropical Atlantic region for lag 0 , suggesting that the trade wind anomalies could modulate dust aerosol through westward transport, dust emission and/or dry deposition: trade winds produce a prevailing easterly component over the tropical Atlantic, thus a positive zonal wind anomaly means a relaxed trade wind, which corresponds to weakened westward dust transport, and possibly stronger dry deposition as well as weaker dust emission over the source region, all resulting in negative aerosol concentration, and vice versa. This strong negative correlation is also evident when the zonal wind anomalies lead the dust anomalies by one MJO phase, indicating that the wind modulation lasts as long as one MJO phase, which is consistent with what was found by Tian et al. [2011]. Negative correlations between dust and precipitation anomalies are also found in lag 0 and lag -1 , but the correlations are much weaker and mostly confined within the convective equatorial region compared to the correlation with the wind anomalies, suggesting moderate MJO modulation on dust aerosol through wet scavenging. Note that some scattered positive correlations are found especially along the South American coast, which might be related to the cloud contamination to the aerosol retrieval.

[44] In contrast with the dust case, examination between the smoke anomalies and the wind and precipitation anomalies suggests that the MJO exhibits very little modulation of the smoke aerosol (right two columns in Figure 10).

[45] Figure 10 shows that dust aerosol is heavily influenced by the MJO through both dynamical and thermodynamical processes, whereas the smoke is not. This might explain the relative magnitude of dust and smoke aerosol anomalies on the intraseasonal time scale. As shown earlier, the MJO composite $\tau_{\text {dust }}$ anomalies are as large as the total $\tau$ anomalies (compare Figures 9a and 10a, and the black and red curves in Figure 9a). Although the MJO related $\tau_{\text {smoke }}$ anomalies are noisy and small, thus difficult to measure, they are about $10 \%$ of the total $\tau$ anomalies, as roughly inferred from Figure 9a. Because the above numbers are based on the composite of strong MJO events only, we further examine the standard deviations of the 30-90 day filtered dust and smoke anomalies, together with those of the total $\tau$ and $\tau_{\text {mar }}$ (Figure 11). It is found that the magnitude of $\tau_{\text {dust }}$ anomalies is comparable to or even larger than that of the total $\tau$, whereas the $\tau_{\text {smoke }}$ anomaly represents about $15 \%$ compared to that of total $\tau$, and $\tau_{\text {mar }}$ shows very little intraseasonal variability, which is overall consistent with what we found based on the composite of strong MJO events. Note that although the intraseasonal $\tau_{\text {dust }}, \tau_{\text {smoke }}$, and $\tau_{\text {mar }}$ anomalies add up to the intraseasonal total $\tau$ anomaly for each day, their variance does not sum to the variance of total $\tau$ for this case, suggesting the individual aerosol components are not 

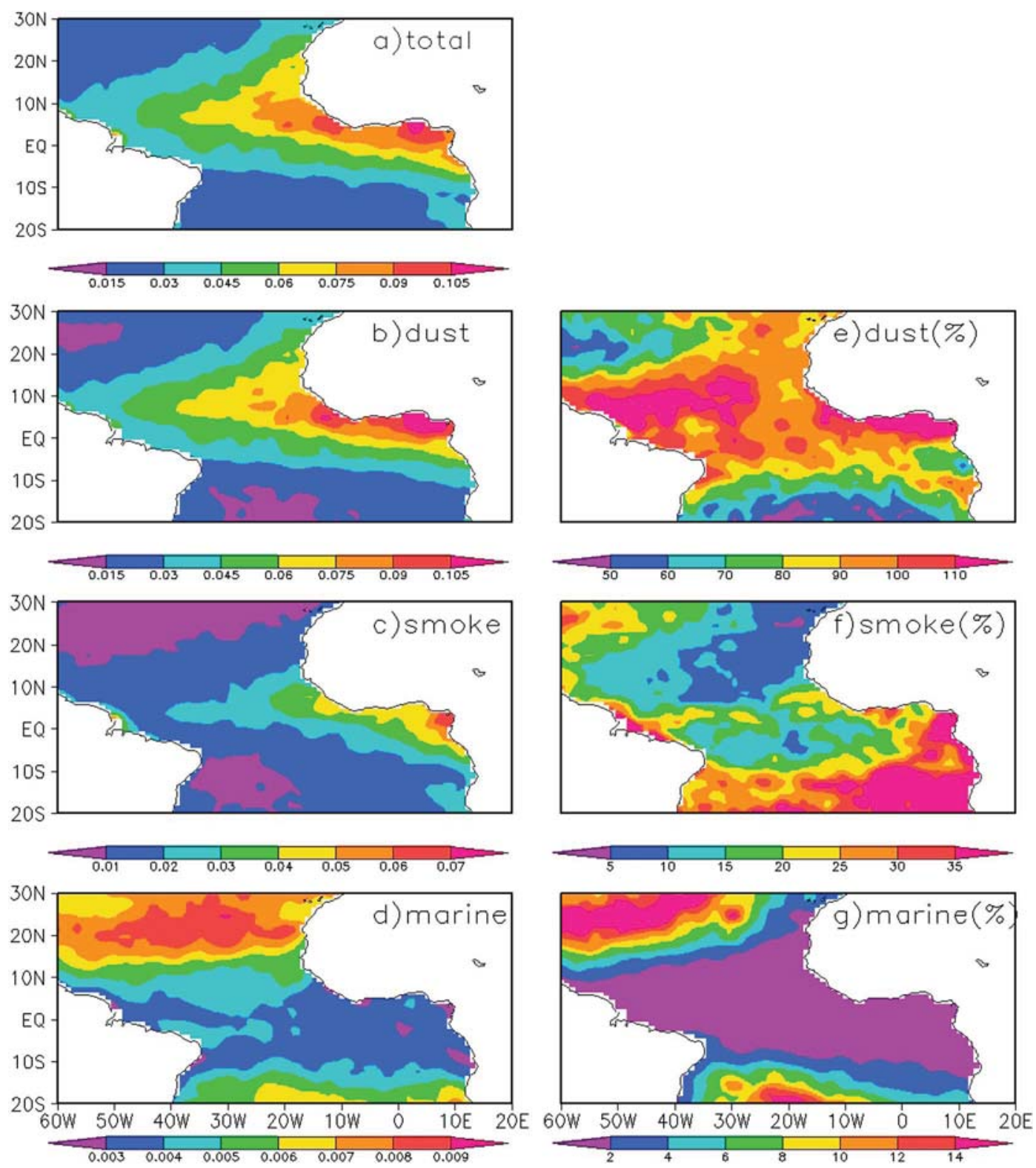

Figure 11. Standard deviation of MODIS aerosol intraseasonal anomalies (30-90 day bandpass filtered)

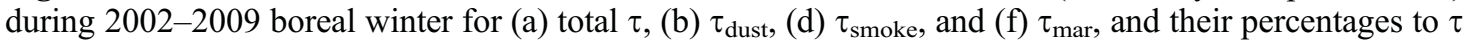
((c) $\tau_{\text {dust }}$, (e) $\tau_{\text {smoke, }}$, and (g) $\left.\tau_{\text {mar }}\right)$. Nine-point spatial smoothing is applied.

completely independent of each other on the intraseasonal time scale, so the nonlinear terms do not vanish.

[46] Recall that $\tau_{\text {dust }}$ is about $40-70 \%$ of total $\tau$, and $\tau_{\text {smoke }}$ and $\tau_{\text {mar }}$ contribute another around $25 \%$ each, in terms of winter climatological mean (Figures 1c, 1e, and 1g), which is quite different from the relative magnitude of $\tau_{\text {dust }}, \tau_{\text {smoke, }}$, and $\tau_{\text {mar }}$ on the intraseasonal time scale as shown above. Thus, we find that although the dominance of dust over smoke and marine aerosols on the intraseasonal time scale can be inferred from their magnitudes in the climatological mean, the former is not necessarily proportional to the latter. Note that the $25 \%$ V.S. $15 \%$ difference in smoke on the climatological and MJO-related scales does not lead to big difference in absolute AOT value, actually is estimated as small as about 0.0015 . Such a small value is likely smaller than the uncertainty in an individual retrieval of the smoke
AOT. Nevertheless, it should be noted that these percentages are obtained by averaging all data during 2002-2009, thus they should be accurate enough in terms of telling the right direction of the change from the climatological scale to the MJO-related scale: For smoke, it is a decrease from $25 \%$ to $15 \%$, while it is an increase from about $40-70 \%$ to about $100 \%$ for dust. Compared to smoke, dust shows an even stronger fluctuation on the intraseasonal time, which is due to the fact that dust is more susceptible to the MJO, as it is more heavily influenced by both the trade wind and precipitation anomalies associated with the MJO.

\section{Summary and Conclusions}

[47] Previous studies [Tian et al., 2011] found significant intraseasonal variability related to the $\mathrm{MJO}$ in the total 
column AOT over the tropical Atlantic region. Aerosol over the tropical Atlantic is primarily a mixture of mineral dust, biomass burning smoke, and marine aerosol. Given the different roles in the radiative forcing and cloud formation processes played by these three aerosol types, as well as the potential predictability of the MJO extending to 2-4 weeks, it is of great interest to further examine the MJO-related variability for individual aerosol types, especially dust and smoke aerosols. In this study, we used two independent and complementary satellite data sets, MODIS and MISR, to investigate the intraseasonal variability of individual aerosol components over the tropical Atlantic.

[48] Daily MODIS/Aqua total AOT and fine-modefraction measurements are used to derive daily $\tau_{\text {dust }}$ and

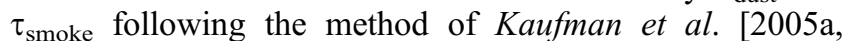
$2005 \mathrm{~b}$. This method contains considerable uncertainties, due to the assumption of constant $f_{\text {dust }}, f_{\text {smoke, }} f_{\text {mar }}$ and the empirical calculation of $\tau_{\text {mar }}$. Strict data rejection has been applied to use Kaufman's formula in a safer way. With MISR's sensitivity to aerosol particle shape, dust and smoke aerosols can be distinguished using the MISR aerosol nonspherical fraction. Because MISR sensitivity to shape diminishes when aerosol concentration is low, only $\tau>=$ 0.15 data are used to compute $\tau_{\text {dust }}$ and $\tau_{\text {smoke }}$ for MISR. The examination of both data sets is necessary, and results from MODIS and MISR are complementary: MODIS provides better spatial coverage, and MISR dust is derived from actual aerosol property retrieval rather than assumed aerosoltype-specific factors.

[49] MODIS and MISR show a very similar dust and smoke winter climatologies. $\tau_{\text {dust }}$ is found to be the dominant aerosol component over the tropical Atlantic. It is largest over the eastern equatorial Atlantic (about 0.35) and gradually decreases toward the west. The contribution of $\tau_{\text {dust }}$ to total $\tau$ ranges from $40 \%$ to $70 \%$, considerably larger than $\tau_{\text {smoke }}$, which contributes approximately $25 \%$, and $\tau_{\text {mar }}$ contributes less than $20 \%$. The daily MODIS and MISR $\tau_{\text {dust }}$ distributions are highly correlated overall, with the correlation coefficients typically about 0.7 over the North Atlantic, but much smaller or even negative over the South Atlantic. MISR $\tau_{\text {dust }}$ is found to be systematically greater than the coincident MODIS $\tau_{\text {dust }}$, and this difference can be traced to the AOT difference between them. The consistency of the MODIS and MISR dust and smoke aerosol climatologies and daily variations lend confidence to our use of these data sets to investigate the relative contributions of dust and smoke aerosols to the total AOT variation associated with the MJO. However, the identification of smoke is much less certain than that of dust, because discrimination among finemode sea salt, sulfate, and smoke particles depends on assumptions for both MODIS and MISR, whereas the MISR dust discrimination is based on retrieved particle shape.

[50] For MODIS, the MJO composite maps of $\tau_{\text {dust }}$ anomalies are very similar to those of $\tau$ anomalies, and are of comparable magnitude. Furthermore, the variance of the $\tau_{\text {dust }}$ anomalies on the full intraseasonal time scale is found to be comparable or even bigger than that of the $\tau$ anomalies. In contrast, the MJO-related $\tau_{\text {smoke }}$ anomalies are rather small, barely exceeding 0.01 , and the $\tau_{\text {mar }}$ anomalies are negligible. The sensitivity study further shows that the MJO-related $\tau_{\text {dust }}$ and $\tau_{\text {smoke }}$ anomalies are quite robust, even when we perturb the $f$ values by their uncertainty ranges or use different sets of $\mathrm{f}$ values from several independent studies.

[51] Similarly, MISR also shows that the MJO composite maps of $\tau_{\text {dust }}$ anomalies are very similar to those of the $\tau$ anomalies, whereas the MJO-related $\tau_{\text {smoke }}$ anomalies are rather small. The composite MJO cycle of $\tau_{\text {dust }}$ anomalies from MISR over the tropical Atlantic Ocean is consistent with the MODIS results, although the anomalies are much noisier due to less frequent sampling. The magnitude of MISR anomalies is again found to be systematically larger than that of MODIS. The MJO-related $\tau_{\text {smoke }}$ anomalies in MISR are overall slightly larger than for MODIS, but still much smaller compared to the $\tau_{\text {dust }}$ anomalies.

[52] The consistency between the MODIS and MISR $\tau_{\text {dust }}$ and $\tau_{\text {smoke }}$ anomalies in terms of the evolution of the MJO cycle and the spatial pattern of anomalies suggests that dust aerosol is the dominant component on the intraseasonal time scale over the tropical Atlantic Ocean, and supports the other main conclusions of this study.

[53] Although dust contributes about $40-70 \%$ to total $\tau$ in terms of climatological mean, its intraseasonal variability is comparable to or even larger than the intraseasonal variability of total $\tau$. The smoke intraseasonal variability is about $15 \%$ of that for total $\tau$, even though its climatological mean contributes to about $25 \%$ of the total $\tau$. This suggests that the MJO does not influence dust and smoke in the exactly same way. Examination of the lag correlation between dust and smoke aerosol anomalies with the low-level zonal wind and precipitation anomalies support this speculation: dust is more susceptible to the MJO as is more heavily influenced by the trade wind and precipitation anomaly associated with the MJO. The modulation of the MJO-related wind anomalies on the dust anomalies can last as long as one MJO phase.

[54] The observational results obtained from two complementary satellite data sets can be used to evaluate chemical transport models and help in model development. Furthermore, the findings of this work have broader implications, related to the predictability issue. As we know, predictability beyond the synoptic time scale relies merely on our knowledge of the semi-periodic phenomena such as the MJO. Given that potential prediction of the MJO is extended to a few weeks currently, our finding suggests that dust has a potential prediction time scale up to a few weeks, too. This adds potential guidance to the prediction of phenomena affected by dust, such as dust storms, Atlantic tropical cyclogenesis, Atlantic tropical cyclone evolution, ocean fertilization, and so on.

\section{Appendix A: MODIS Data Rejection}

[55] In this work, data rejection is performed for the MODIS $\tau$ and $f$ measurements for the reasons described below.

[56] The dependence of $\tau_{\text {dust }}$ and $\tau_{\text {smoke }}$ on $\tau$ and $f$ based on equations (3) and (4) is illustrated in Figure A1a and A1b, where $\tau_{\text {mar }}$ is set to 0.06 (the approximate global mean value of $\tau_{\text {mar }}$ ). It is seen that the larger the $\tau$, the larger $\tau_{\text {dust }}$ and $\tau_{\text {smoke. }}$ Also, as $f$ increases, $\tau_{\text {smoke }}$ increases and $\tau_{\text {dust }}$ decreases. It is shown that equations (3) and (4) can produce reasonable (nonnegative) values for both $\tau_{\text {dust }}$ and $\tau_{\text {smoke }}$ only when the paired $\tau$ and $f$ measurements fall within a limited region bounded by the white dashed lines $\left(\tau_{\text {dust }}=-0.03\right.$ 


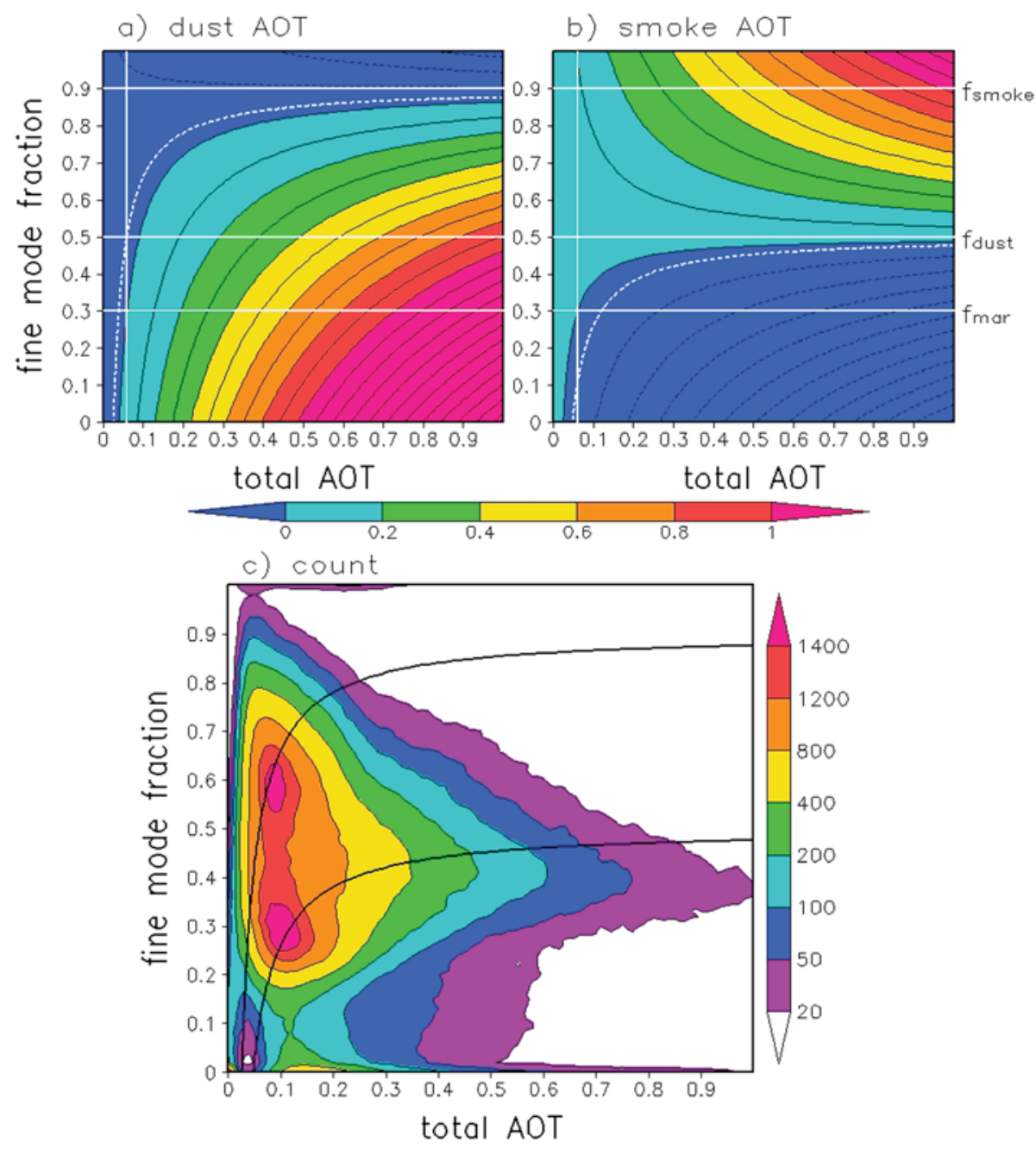

Figure A1. Calculated (a) $\tau_{\text {dust }}$ and (b) $\tau_{\text {smoke }}$ as a function of total $\tau$ and $\mathrm{f}$ according to equations (3) and (4). Here $f_{\text {mar }}=0.3, f_{\text {dust }}=0.5, f_{\text {smoke }}=0.9$, and $\tau_{\text {mar }}=0.06$, as indicated by four white straight lines. The white dashed lines indicate $\tau_{\text {dust }}=-0.03$ and $\tau_{\text {smoke }}=-0.03$. Contour interval: 0.1 . (c) The count of paired MODIS $\tau$ and f measurements with respect to $\tau$ and $f$ over the tropical Atlantic $\left(20^{\circ} \mathrm{S}-30^{\circ} \mathrm{N}, 60^{\circ} \mathrm{W}-20^{\circ} \mathrm{E}\right)$ for 2002-2009 boreal winters. Superimposed solid black lines are the two white dashed lines in Figures A1a and A1b corresponding to $\tau_{\text {dust }}=-0.03$ and $\tau_{\text {smoke }}=-0.03$.

and $\left.\tau_{\text {smoke }}=-0.03\right)$. We relax the limit of $\tau_{\text {dust }}$ or $\tau_{\text {smoke }}$ to -0.03 instead of 0 because the uncertainties of the MODIS AOT are \pm 0.03 over ocean, thus a small negative AOT up to -0.03 is regarded as indistinguishable from the value 0 [Remer et al., 2005]. Note that calculated $\tau_{\text {dust }}$ and $\tau_{\text {smoke }}$ in the range of 0 to -0.03 have been set to zero. Outside this region, either $\tau_{\text {dust }}$ or $\tau_{\text {smoke }}$ is too negative, and correspondingly, $\tau_{\text {smoke }}$ or $\tau_{\text {dust }}$ would be larger than the total AOT, which is not physical. Therefore, the $\tau$ and f measurements giving rise to such $\tau_{\text {dust }}$ and $\tau_{\text {smoke }}$ values are rejected. In addition, $\tau$ measurements greater than 2 are excluded, given the large uncertainties from possible cloud contamination [Zhang et al., 2005].

[57] The count distribution of paired MODIS $\tau$ and $f$ measurements as a function of $\tau$ and $\mathrm{f}$ is summarized for the tropical Atlantic $\left(20^{\circ} \mathrm{S}-30^{\circ} \mathrm{N}, 60^{\circ} \mathrm{W}-20^{\circ} \mathrm{E}\right)$ and for the 2002-2009 boreal winters (October to April) in Figure A1c. It is found that the majority of observations fall within the region bounded by two lines $\left(\tau_{\text {dust }}=-0.03\right.$ and $\tau_{\text {smoke }}=$ $-0.03)$; however, there is also a large number of observations falling outside the two lines, which are rejected in the calculation. The rejection results from both the limitations in MODIS data and the limitations in Kaufman's method. For example, in some cases $\tau$ is typically between $0.1-0.3$, which is much larger than the baseline $\tau_{\text {mar, }}$, while $\mathrm{f}$ is extremely small, nearly 0 (see bottom of Figure A1c). These observations are very likely artifacts of cloud contamination [e.g., Tian et al., 2008; Zhang et al., 2005; Huang et al., 2012]. Possible contamination also comes from the bias in the sea surface reflectance [Sayer et al., 2010; Grandey et al., 2011]. For other cases, $\tau$ is also significantly larger than $\tau_{\text {mar }}$ and $f$ falls between $f_{\text {mar }}$ and $f_{\text {dust }}$, suggesting the aerosol is a mixture of dust and sea salt (see the area between the lower solid line and the $\mathrm{f}=0.3$ line in Figure A1c). These are likely valid observations; however, due to the difficulties in separating dust from sea salt over this regime [Kaufman et al., 2005a, 2005b], we do not include these observations in our calculations.

[58] Before data rejection, MODIS aerosol observations are available for about $70 \%$ of the days during 2002-2009 
boreal winters over the clear subtropical North Atlantic, and decreases to about $35 \%$ over the cloudy equatorial Atlantic. The data rejection procedure described above rejects somewhat less than half of the observations. The most frequent rejections occur over the subtropical oceans, possibly due to the ambiguity between sea salt and dust aerosol over those regions.

[59] Acknowledgments. This research was performed at Jet Propulsion Laboratory (JPL), California Institute of Technology (Caltech), under a contract with National Aeronautics and Space Administration (NASA) It was supported in part by the National Science Foundation (NSF) grant ATM-0840755 at University of California, Los Angeles. The work of R. Kahn is supported in part by NASA's Climate and Radiation Research and Analysis Program, under H. Maring, NASA's Atmospheric Composition Program under R. Eckman, and the EOS-MISR project. The MODIS/ Aqua data used in this study have been obtained from the NASA LAADS server and ERA-Interim data used in this study have been obtained from the ECMWF Data Server. (C) 2011. All rights reserved.

\section{References}

Abdou, W. A., D. J. Diner, J. V. Martonchik, C. J. Bruegge, R. A. Kahn, B. J. Gaitley, K. A. Crean, L. A. Remer, and B. Holben (2005), Comparison of coincident Multiangle Imaging Spectroradiometer and Moderate Resolution Imaging Spectroradiometer aerosol optical depths over land and ocean scenes containing Aerosol Robotic Network sites, J. Geophys. Res., 110, D10S07, doi:10.1029/2004JD004693.

Bellouin, N., O. Boucher, J. Haywood, and M. S. Reddy (2005), Global estimate of aerosol direct radiative forcing from satellite measurements, Nature, 438(7071), 1138-1141, doi:10.1038/nature04348.

Chen, W.-T., R. Kahn, D. Nelson, K. Yau, and J. Seinfeld (2008), Sensitivity of multi-angle imaging to optical and microphysical properties of biomass burning aerosols, J. Geophys. Res. 113, D10203, doi:10.1029/ 2007JD009414.

Dee, D. P., et al. (2011), The ERA-Interim reanalysis: Configuration and performance of the data assimilation system, $Q$. J. Roy. Meteorol. Soc., 137(656), 553-597, doi:10.1002/qj.828.

Grandey, B. S., P. Stier, T. M. Wagner, R. G. Grainger, and K. I. Hodges (2011), The effect of extratropical cyclones on satellite-retrieved aerosol properties over ocean, Geophys. Res. Lett., 38, L13805, doi:10.1029/ 2011 GL047703.

Huang, J. F., C. D. Zhang, and J. M. Prospero (2010), African dust outbreaks: A satellite perspective of temporal and spatial variability over the tropical Atlantic Ocean, J. Geophys. Res., 115, D05202, doi:10.1029/ 2009jd012516.

Huang, J., et al. (2012), Evaluations of cirrus contamination and screening in ground aerosol observations using collocated lidar systems, J. Geophys. Res., 117, D15204, doi:10.1029/2012JD017757.

Huffman, G. J., R. F. Adler, D. T. Bolvin, G. J. Gu, E. J. Nelkin, K. P. Bowman, Y. Hong, E. F. Stocker, and D. B. Wolff (2007), The TRMM multisatellite precipitation analysis (TMPA): Quasi-global, multiyear, combined-sensor precipitation estimates at fine scales, J. Hydrometeorol., 8(1), 38-55, doi:10.1175/jhm560.1

Husar, R. B., J. M. Prospero, and L. L. Stowe (1997), Characterization of tropospheric aerosols over the oceans with the NOAA Advanced Very High Resolution Radiometer optical thickness operational product, J. Geophys. Res., 102(D14), 16889-16909.

Jones, T. A., and S. A. Christopher (2007), MODIS derived fine mode fraction characteristics of marine, dust, and anthropogenic aerosols over the ocean, constrained by GOCART, MOPITT, and TOMS, J. Geophys. Res., 112, D22204, doi:10.1029/2007jd008974.

Jones, T. A., and S. A. Christopher (2011), A reanalysis of MODIS fine mode fraction over ocean using OMI and daily GOCART simulations, Atmos. Chem. Phys., 11(12), 5805-5817, doi:10.5194/acp-11-5805-2011.

Kahn R. A., R. West, D. McDonald, B. Rheingans, and M. I. Mishchenko (1997), Sensitivity of Multi-angle remote sensing observations to aerosol sphericity, J. Geophys. Res., 102, 16,861-16,870.

Kahn, R., P. Banerjee, D. McDonald, and D. J. Diner (1998), Sensitivity of multiangle imaging to aerosol optical depth and to pure-particle size distribution and composition over ocean, J. Geophys. Res., 103(D24), 32,195-32,213, doi:10.1029/98JD01752.

Kahn, R., P. Banerjee, and D. McDonald (2001), The sensitivity of multiangle imaging to natural mixtures of aerosols over ocean, J. Geophys. Res., 106(D16), 18,219-18,238, doi:10.1029/2000JD900497.

Kahn, R. A., D. L. Nelson, M. Garay, R. C. Levy, M. A. Bull, D. J. Diner, J. V. Martonchik, S. R. Paradise, E. G. Hansen, and L. A. Remer (2009),
MISR Aerosol product attributes, and statistical comparisons with MODIS, IEEE Trans. Geosci. Rem. Sens., 47, 4095-4114.

Kahn, R. A., B. J. Gaitley, M. J. Garay, D. J. Diner, T. Eck, A. Smirnov, and B. N. Holben (2010), MISR aerosol product assessment by comparison with AERONET, J. Geophys. Res., 115, D23209, doi:10.1029/2010JD014601.

Kalashnikova, O. V., and R. Kahn (2006), Ability of multiangle remote sensing observations to identify and distinguish mineral dust types: Sensitivity over dark water, J. Geophys. Res., 111, D11207, doi:10.1029/2005JD006756.

Kalashnikova, O. V., and R. A. Kahn (2008), Mineral dust plume evolution over the Atlantic from MISR and MODIS aerosol retrievals, J. Geophys. Res., 113, D24204, doi:10.1029/2008JD010083.

Kalashnikova, O. V., R. Kahn, I. N. Sokolik, and W.-H. Li (2005), The ability of multi-angle remote sensing observations to identify and distinguish mineral dust types: Optical models and retrievals of optically thick plumes, J. Geophys. Res., 110, D18S14, doi:10.1029/2004JD004550.

Kaufman, Y. J., A. Smirnov, B. N. Holben, and O. Dubovik (2001), Baseline maritime aerosol: Methodology to derive the optical thickness and scattering properties, Geophys. Res. Lett., 28(17), 3251-3254.

Kaufman, Y. J., D. Tanre, and O. Boucher (2002), A satellite view of aerosols in the climate system, Nature, 419(6903), 215-223.

Kaufman, Y. J., O. Boucher, D. Tanre, M. Chin, L. A. Remer, and T. Takemura (2005a), Aerosol anthropogenic component estimated from satellite data, Geophys. Res. Lett., 32, L17804, doi:10.1029/2005g1023125.

Kaufman, Y. J., I. Koren, L. A. Remer, D. Tanre, P. Ginoux, and S. Fan (2005b), Dust transport and deposition observed from the Terra-Moderate Resolution Imaging Spectroradiometer (MODIS) spacecraft over the Atlantic ocean, J. Geophys. Res., 110, D10S12, doi:10.1029/2003jd004436.

Kleidman, R. G., N. T. O’Neill, L. A. Remer, Y. J. Kaufman, T. F. Eck D. Tanre, O. Dubovik, and B. N. Holben (2005), Comparison of moderate resolution imaging spectroradiometer (MODIS) and aerosol robotic network (AERONET) remote-sensing retrievals of aerosol fine mode fraction over ocean, J. Geophys. Res., 110, D22205, doi:10.1029/2005jd005760.

Lau, W. K. M., and D. E. Waliser (Eds.) (2005), Intraseasonal Variability of the Atmosphere-ocean Climate System, 474 pp., Springer, Heidelberg, Germany.

Levy, R. C., L. A. Remer, D. Tanré, S. Mattoo, and Y. J. Kaufman (2009), Algorithm for remote sensing of tropospheric aerosol over dark targets from MODIS: Collections 005 and 051, revision 2. MODIS algorithm theoretical basis document.

Levy, R. C., L. A. Remer, R. G. Kleidman, S. Mattoo, C. Ichoku, R. Kahn, and T. F. Eck (2010), Global evaluation of the collection 5 MODIS dark-target aerosol products over land, Atmos. Chem. Phys., 10(21), 10399-10420, doi:10.5194/acp-10-10399-2010.

Li, K. F., B. Tian, D. E. Waliser, and Y. L. Yung (2010), Tropical midtropospheric $\mathrm{CO} 2$ variability driven by the Madden-Julian oscillation Proc. Nat. Acad. Sci. USA, 107(45), 19171-19175, doi:10.1073/ pnas. 1008222107

Li, K.-F., B. Tian, D. E. Waliser, M. J. Schwartz, J. L. Neu, J. R. Worden, and Y. L. Yung (2011), Vertical structure of MJO-related subtropical ozone variations from MLS, TES, and SHADOZ data, Atmos. Chem. Phys. Discuss., 11, 24503-24533, doi:10.5194/acpd-11-24503-2011.

Madden, R. A., and P. R. Julian (1971), Detection of a 40-50 day oscillation in the zonal wind in the tropical Pacific, J. Atmos. Sci., 28(7), 702-708.

Madden, R. A., and P. R. Julian (1972), Description of global-scale circulation cells in tropics with a 40-50 day period, J. Atmos. Sci., 29(6), 1109-1123.

Maring, H., D. L. Savoie, M. A. Izaguirre, L. Custals, and J. S. Reid (2003), Mineral dust aerosol size distribution change during atmospheric transport, J. Geophys. Res., 108(D19), 8592, doi:10.1029/2002jd002536.

Reid, J. S., P. Xian, E. J. Hyer, M. K. Flatau, E. M. Ramirez, F. J. Turk, C. R. Sampson, C. Zhang, E. M. Fukada, and E. D. Maloney (2012), Multi-scale meteorological conceptual analysis of observed active fire hotspot activity and smoke optical depth in the Maritime Continent Atmos. Chem. Phys., 12, 2117-2147, doi:10.5194/acp-12-2117-2012.

Remer, L. A., et al. (2005), The MODIS aerosol algorithm, products, and validation, J. Atmos. Sci., 62(4), 947-973.

Sayer, A. M., G. E. Thomas, and R. G. Grainger (2010), A sea surface reflectance model for (A)ATSR, and application to aerosol retrievals, Atmos. Meas. Tech., 3, 813-838, doi:10.5194/amt-3-813-2010.

Smirnov, A., B. N. Holben, T. F. Eck, O. Dubovik, and I. Slutsker (2003), Effect of wind speed on columnar aerosol optical properties at Midway Island, J. Geophys. Res., 108(D24), 4802, doi:10.1029/2003JD003879.

Tian, B., and D. E. Waliser (2011), Chemical and biological impacts, Ch. 18, in Intraseasonal variability in the atmosphere-ocean climate system, 2nd ed., edited by W. K. M. Lau and D. E. Waliser, Springer, Heidelberg, Germany.

Tian, B., Y. L. Yung, D. E. Waliser, T. Tyranowski, L. Kuai, E. J. Fetzer, and F. W. Irion (2007), Intraseasonal variations of the tropical total ozone and their connection to the Madden-Julian Oscillation, Geophys. Res. Lett., 34, L08704, doi:10.1029/2007GL029451. 


\section{GUO ET AL.: ATLANTIC DUST AND SMOKE}

Tian, B., D. E. Waliser, R. A. Kahn, Q. Li, Y. L. Yung, T. Tyranowski, I. V. Geogdzhayev, M. I. Mishchenko, O. Torres, and A. Smirnov (2008),

Does the Madden-Julian Oscillation influence aerosol variability?, J. Geophys. Res., 113, D12215, doi:10.1029/2007jd009372.

Tian, B., D. E. Waliser, R. A. Kahn, and S. Wong (2011), Modulation of Atlantic aerosols by the Madden-Julian Oscillation, J. Geophys. Res., 116, D15108, doi:10.1029/2010JD015201.

Waliser, D. E. (2005), Predictability and forecasting, Ch. 12, in Intraseasonal Variability of the Atmosphere-ocean Climate System, edited by W. K. M. Lau and D. E. Waliser, pp. 389-424, Springer, Heidelberg, Germany.

Waliser, D., et al. (2009), MJO simulation diagnostics, J. Climate, 22(11), 3006-3030, doi:10.1175/2008jcli2731.1.

Weare, B. C. (2010), Madden-Julian Oscillation in the tropical stratosphere, J. Geophys. Res., 115, D17113, doi:10.1029/2009jd013748.

Wheeler, M. C., and H. H. Hendon (2004), An all-season real-time multivariate MJO index: Development of an index for monitoring and prediction, Mon. Wea. Rev., 132(8), 1917-1932, doi:10.1175/1520-0493 (2004) $132<1917$ :aarmmi $>2.0 . c 0 ; 2$.

Wong, S., and A. E. Dessler (2007), Regulation of $\mathrm{H} 2 \mathrm{O}$ and CO in tropical tropopause layer by the Madden-Julian oscillation, J. Geophys. Res., 112, D14305, doi:10.1029/2006jd007940.

Yu, H. B., M. Chin, L. A. Remer, R. G. Kleidman, N. Bellouin, H. S. Bian, and T. Diehl (2009), Variability of marine aerosol fine-mode fraction and estimates of anthropogenic aerosol component over cloud-free oceans from the Moderate Resolution Imaging Spectroradiometer (MODIS), J. Geophys. Res., 114, D10206, doi:10.1029/2008jd010648.

Zhang, C. (2005), The Madden-Julian Oscillation, Rev. Geophys., 43, RG2003, doi:10.1029/2004RG000158.

Zhang, J. L., J. S. Reid, and B. N. Holben (2005), An analysis of potential cloud artifacts in MODIS over ocean aerosol optical thickness products, Geophys. Res. Lett., 32, L155803, doi:10.1029/ $2005 \mathrm{~g} 1023254$ 